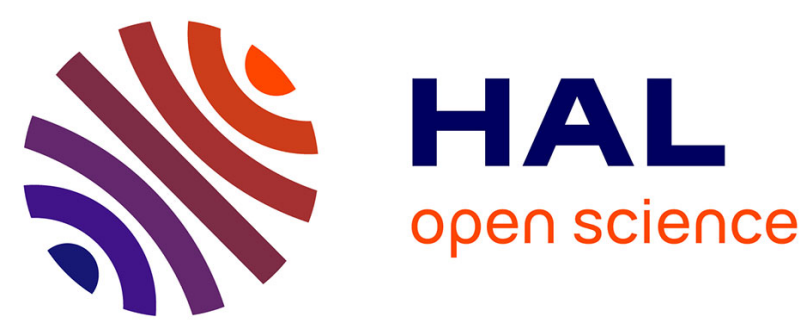

\title{
Chromatin landscape dynamics in the early development of the plant parasitic nematode Meloidogyne incognita
} Rahim Hassanaly-Goulamhoussen, Ronaldo de Carvalho Augusto, Nathalie Marteu-Garello, Arthur Péré, Bruno Favery, Martine da Rocha, Etienne G J Danchin, Pierre Abad, Christoph Grunau, Laetitia Perfus-Barbeoch, et al.

\section{To cite this version:}

Rahim Hassanaly-Goulamhoussen, Ronaldo de Carvalho Augusto, Nathalie Marteu-Garello, Arthur Péré, Bruno Favery, et al.. Chromatin landscape dynamics in the early development of the plant parasitic nematode Meloidogyne incognita. Frontiers in Cell and Developmental Biology, 2021, 9, pp.765690. 10.1101/2021.05.11.443567 . hal-03467409

\section{HAL Id: hal-03467409 \\ https://hal.science/hal-03467409}

Submitted on 6 Dec 2021

HAL is a multi-disciplinary open access archive for the deposit and dissemination of scientific research documents, whether they are published or not. The documents may come from teaching and research institutions in France or abroad, or from public or private research centers.
L'archive ouverte pluridisciplinaire HAL, est destinée au dépôt et à la diffusion de documents scientifiques de niveau recherche, publiés ou non, émanant des établissements d'enseignement et de recherche français ou étrangers, des laboratoires publics ou privés. 


\section{OPEN ACCESS}

Edited by:

Jonathan B Weitzman,

Université Paris Diderot, France

Reviewed by:

Davide Andrenacci,

National Research Council (CNR), Italy

Lei Zhao,

University of Wisconsin-Madison, United States

${ }^{*}$ Correspondence: Laetitia Perfus-Barbeoch laetitia.zurletto@univ-cotedazur.fr

Christoph Grunau

christoph.grunau@univ-perp.fr

Specialty section:

This article was submitted to Epigenomics and Epigenetics,

a section of the journal

Frontiers in Cell and Developmental

Biology

Received: 27 August 2021 Accepted: 03 November 2021 Published: 06 December 2021

Citation:

Hassanaly-Goulamhoussen $R$,

De Carvalho Augusto $R$, Marteu-Garello N, Péré A, Favery B, Da Rocha M, Danchin EGJ, Abad P,

Grunau $C$ and Perfus-Barbeoch $L$

(2021) Chromatin Landscape

Dynamics in the Early Development of

the Plant Parasitic Nematode

Meloidogyne incognita.

Front. Cell Dev. Biol. 9:765690.

doi: 10.3389/fcell.2021.765690

\section{Chromatin Landscape Dynamics in the Early Development of the Plant Parasitic Nematode Meloidogyne incognita}

\author{
Rahim Hassanaly-Goulamhoussen ${ }^{1}$, Ronaldo De Carvalho Augusto ${ }^{2,3}$, \\ Nathalie Marteu-Garello ${ }^{1}$, Arthur Péré ${ }^{1}$, Bruno Favery ${ }^{1}$, Martine Da Rocha ${ }^{1}$, \\ Etienne G. J. Danchin ${ }^{1}$, Pierre Abad ${ }^{1}$, Christoph Grunau ${ }^{2 *}$ and Laetitia Perfus-Barbeoch ${ }^{1 *}$ \\ ${ }^{1}$ Université Côte d'Azur, INRAE, CNRS, ISA, Sophia Antipolis, France, ${ }^{2} I H P E$, Univ Perpignan Via Domitia, CNRS, IFREMER, Univ \\ Montpellier, Perpignan, France, ${ }^{3}$ Laboratory of Biology and Modeling of the Cell, Ecole Normale Supérieure de Lyon, CNRS, \\ Université Claude Bernard de Lyon, Université de Lyon, Lyon, France
}

In model organisms, epigenome dynamics underlies a plethora of biological processes. The role of epigenetic modifications in development and parasitism in nematode pests remains unknown. The root-knot nematode Meloidogyne incognita adapts rapidly to unfavorable conditions, despite its asexual reproduction. However, the mechanisms underlying this remarkable plasticity and their potential impact on gene expression remain unknown. This study provides the first insight into contribution of epigenetic mechanisms to this plasticity, by studying histone modifications in $M$. incognita. The distribution of five histone modifications revealed the existence of strong epigenetic signatures, similar to those found in the model nematode Caenorhabditis elegans. We investigated their impact on chromatin structure and their distribution relative to transposable elements (TE) loci. We assessed the influence of the chromatin landscape on gene expression at two developmental stages: eggs, and preparasitic juveniles. H3K4me3 histone modification was strongly correlated with high levels of expression for protein-coding genes implicated in stage-specific processes during $M$. incognita development. We provided new insights in the dynamic regulation of parasitism genes kept under histone modifications silencing. In this pioneering study, we establish a comprehensive framework for the importance of epigenetic mechanisms in the regulation of the genome expression and its stability in plant-parasitic nematodes.

Keywords: histone modifications, epigenetics, root-knot nematode, development, parasitism

\section{INTRODUCTION}

Crops are continually attacked by a wide range of pests and parasites. Plant-parasitic nematodes are thought to be one of the main causes of damages in food crops, resulting in yield losses of more than $\$ 150$ billion worldwide (Singh et al., 2013). Root knot nematodes (RKN), Meloidogyne spp., are among the most rapidly spreading of all crop pests and pathogens (Bebber et al., 2014). Their rapid spread may have been facilitated by their wide host range, high fecundity, and parthenogenetic reproduction, allowing infestations to become established with relatively few individuals (Singh et al., 2013). Understanding the determinants of the extreme adaptive capacity of RKN is crucial for the development of effective and sustainable control methods. 
Meloidogyne incognita is the most ubiquitous RKN with an obligate biotroph lifestyle. It feeds exclusively on living cells within the vascular cylinder of the root (Caillaud et al., 2008). The freshly hatched second-stage pre-parasitic juveniles (J2s) within the soil are attracted to the root tip of the host plant. These microscopic J2s ( $400 \mu \mathrm{m}$ long and $15 \mu \mathrm{m}$ wide) invade host roots close to the root elongation zone, through the physical and enzymatic destruction of plant cell walls in the root epidermis, eventually reaching the vascular cylinder, where they establish a permanent feeding site (Favery et al., 2020). To this end, infective juveniles secrete molecules known as effectors, to induce major cellular changes in recipient host cells and evade plant defense responses. These effector proteins are translocated directly from the secretory gland cells into the host cells by a syringe-like structure, called stylet (Mejias et al., 2019). The tissue around the permanent feeding site typically shows signs of hyperplasia, resulting in the characteristic knot-like shape of roots infected with RKN. Once they begin feeding, the J2s become sedentary, going through three molts before becoming mature adults. The females release eggs onto the root surface, and embryogenesis within the eggs is followed by the first molt, generating secondstage juveniles. Males are produced in unfavorable conditions (e.g., resistant host), and they migrate out of the plant without developing further and without playing a role in reproduction (Castagnone-Sereno, 2006).

Despite its mitotic parthenogenetic mode of reproduction, presumably resulting in low genetic plasticity, $M$. incognita can adapt rapidly to unfavorable conditions (Castagnone-Sereno and Danchin, 2014; Koutsovoulos et al., 2020). The mechanisms underlying this adaptability have yet to be elucidated. Population genomics analyses have revealed only low genome variability at the SNP level between $M$. incognita isolates across the globe (Koutsovoulos et al., 2020). Furthermore, these point mutations did not correlate with the ranges of compatible plant host species. A follow-up population genomics study on Japanese isolates (Asamizu et al., 2020) confirmed the low genome variability at the SNP level but identified some correlations with infection compatibility of different cultivars of the same plant species (sweet potato). Taken together, these studies suggest point mutations are not the sole genome plasticity factors involved in the adaptive evolution of $M$. incognita. Consequently, other genome plasticity factors have also been investigated in this species, including movements of transposable elements (TE) and gene copy number variations $(\mathrm{CNV})$. High similarity between TE copies and their consensus sequences suggest they have been recently active in the $M$. incognita genome (Kozlowski et al., 2021). Studying variations of their frequencies across geographical isolates allowed identification of isolate-specific TE insertions, including in coding or regulatory regions, suggesting $\mathrm{TE}$ movements might constitute a genome plasticity factor with functional consequences. However, no evidence yet for an adaptive role of these movements was shown in this species and nothing is known about the mechanisms underlying their regulation or amplification. In addition, convergent gene $\mathrm{CNV}$ have been shown to correlate with rapid breaking down of tomato plant resistance, suggesting an adaptive role, although causative relation has not yet been shown (CastagnoneSereno et al., 2019) and the underlying mechanisms are also unknown. Because a strategy to explain $M$. incognita's capacity to adapt in a fast-fluctuating environment is lacking, investigating whether epigenetic mechanisms do occur and have possible impact on genome regulation is timely. Indeed, the epigenetic control of transposable elements has been identified as an important factor of genome evolution (Choi and Lee, 2020). Furthermore, the epigenome dynamics of multicellular organisms are associated with transitions in cell cycle development, germline specification, gametogenesis, and inheritance. Within the cell, nuclear DNA is packaged and ordered into chromatin by histone proteins (Talbert and Henikoff, 2010; Gornik et al., 2012). Chromatin can adopt different conformational states directly influencing gene expression, from relaxed transcriptionally active euchromatin to condensed transcriptionally inactive heterochromatin. Specific enzymes regulate histone structure and function through chemical modifications to the histone proteins, such as acetylation and methylation. In many organisms, euchromatin displays an enrichment in the di- (or tri-) methylation of the lysine 4 residue of histone 3 (H3K4me3), whereas heterochromatin displays enrichment in the trimethylation of the lysine 9 or lysine 27 residue of histone 3 (H3K9me3 and H3K27me3) (Soyer et al., 2014). Specific combinations of histone modifications are associated with transcriptionally permissive or repressive chromatin structures, thereby controlling gene expression at the transcriptional level (Strahl and Allis, 2000). Other organisms, such as Saccharomyces cerevisiae, display an unusual regulation of histone modifications, with a lack of $\mathrm{H} 3 \mathrm{~K} 9 \mathrm{me} 3$ modification and the establishment of alternative modifications defining the silent state of chromatin (O'Kane and Hyland, 2019).

Chromatin immunoprecipitation followed by high-throughput sequencing (ChIP-seq) is a powerful method for generating genomewide maps of interactions between proteins and DNA, including posttranslational histone modifications, and for mapping histone variants (Meyer and Liu, 2014). Extensive epigenetic studies have been performed in the model nematode Caenorhabditis elegans, addressing its functional genomic elements, including histone modifications in response to the environment (Weinhouse et al., 2018). Previous studies have shown that $M$. incognita lacks 5methylcytosine $(5 \mathrm{mC})$ and has no cytosine-DNA (cytosine-5)methyltransferase 1 (DNMT1) or DNMT3 (Perfus-Barbeoch et al., 2014; Pratx et al., 2017) which is similar to what is known for C. elegans (Wenzel et al., 2011). Low-level DNA N (6)methylation (6 mA-DNA) has been identified as an alternative carrier of epigenetic information in C. elegans (Greer et al., 2015). However, the physiological relevance of 6-mA-DNA remains unclear. Apart from this model species, the role of chromatin modifications has not been studied in nematodes. The studies performed to date have been limited to bioinformatics analyses indicating that potential homologs of canonical histone-modifying enzymes are conserved in the genomes of C. elegans and two parasitic nematodes, the food-borne animal parasite Trichinella spiralis and the plant parasite M. incognita (Mitreva et al., 2011; Pratx et al., 2017). Epigenetic regulation is considered a key mechanism of parasite adaptation, and its role in plant-nematode interactions is an emerging field of study (Hewezi, 2020).

Deciphering histone modifications and their effects on gene transcription is important for understanding the key parameters 
TABLE 1 | Overall coverage frequencies of ChIP-Seq data. Overall alignment (bp) and genomic coverage percentage of H3K4me3, H3K9me3, H3K27ac, H3K27me3 and H4K20me1 histone modifications and their combinations over the whole M. incognita genome and the Transposable Element annotations (TE), for Egg and J2 samples. $M$. incognita genome has been fragmented in silico into $500 \mathrm{bp}$ bins on which histone modification enrichment was predicted with a posterior probability $>0.5$. If a histone modification was predicted, the corresponding $500 \mathrm{bp}$ bin was counted. Coverage frequencies were calculated based on $184 \mathrm{Mb}$ total $\mathrm{M}$. incognita genome size. Three biological replicates of $M$. incognita eggs and J2s have been treated jointly to identify common histone modification enrichment using ChromstaR.

\begin{tabular}{|c|c|c|c|c|c|c|}
\hline $\begin{array}{l}\text { Histone modification } \\
\text { combination }\end{array}$ & $\begin{array}{l}\text { Whole-genome } \\
\text { coverage } \\
\text { in eggs } \\
\text { (bp) }\end{array}$ & $\begin{array}{l}\text { Whole-genome } \\
\text { coverage } \\
\text { in } \mathrm{J} 2 \mathrm{~s} \\
\text { (bp) }\end{array}$ & $\begin{array}{l}\text { Proportion of } \\
\text { whole } \\
\text { genome } \\
\text { in eggs } \\
(\%)\end{array}$ & $\begin{array}{l}\text { Proportion of } \\
\text { whole } \\
\text { genome } \\
\text { in J2s } \\
(\%)\end{array}$ & $\begin{array}{l}\text { Proportion } \\
\text { in } \\
\text { TE in } \\
\text { eggs (\%) }\end{array}$ & $\begin{array}{c}\text { Proportion } \\
\text { in } \\
\text { TE in } \\
\text { J2s (\%) }\end{array}$ \\
\hline [H3K4me3] & $25,235,500$ & $26,575,000$ & 13.861 & 14.597 & 2.899 & 3.129 \\
\hline [H4K2Ome1] & $6,900,000$ & $6,535,000$ & 3.79 & 3.59 & 1.747 & 2.104 \\
\hline [H3K9me3] & $6,379,000$ & $6,033,500$ & 3.504 & 3.314 & 8.614 & 7.108 \\
\hline [H3K27me3] & $4,036,000$ & $5,004,500$ & 2.217 & 2.749 & 1.73 & 2.421 \\
\hline [H3K9me3+H4K2Ome1] & $3,676,500$ & $3,062,500$ & 2.019 & 1.682 & 5.944 & 4.756 \\
\hline$[\mathrm{H} 3 \mathrm{~K} 27 \mathrm{ac}]$ & $2,991,500$ & $2,528,000$ & 1.643 & 1.389 & 0.434 & 0.386 \\
\hline [H3K27me3+H3K9me3+H4K2Ome1] & $2,737,500$ & $2,499,500$ & 1.504 & 1.373 & 4.283 & 4.05 \\
\hline [H3K27me3+H4K2Ome1] & $2,698,000$ & $3,431,500$ & 1.482 & 1.885 & 1.387 & 2.239 \\
\hline$[\mathrm{H} 3 \mathrm{~K} 27 \mathrm{ac}+\mathrm{H} 4 \mathrm{~K} 20 \mathrm{me} 1]$ & $1,857,500$ & $1,478,000$ & 1.02 & 0.812 & 0.29 & 0.214 \\
\hline$[\mathrm{H} 3 \mathrm{~K} 4 \mathrm{me} 3+\mathrm{H} 3 \mathrm{~K} 9 \mathrm{me}]$ & $1,580,500$ & 836,000 & 0.868 & 0.459 & 0.18 & 0.115 \\
\hline$[\mathrm{H} 3 \mathrm{~K} 27 \mathrm{ac}+\mathrm{H} 3 \mathrm{~K} 27 \mathrm{me} 3+\mathrm{H} 4 \mathrm{~K} 20 \mathrm{me} 1]$ & $1,519,000$ & $1,643,500$ & 0.834 & 0.903 & 0.362 & 0.434 \\
\hline [H3K4me3+H4K2Ome1] & $1,263,500$ & $1,263,000$ & 0.694 & 0.694 & 0.194 & 0.168 \\
\hline$[\mathrm{H} 3 \mathrm{~K} 27 \mathrm{ac}+\mathrm{H} 3 \mathrm{~K} 4 \mathrm{me} 3]$ & 685,000 & 624,500 & 0.376 & 0.343 & 0.091 & 0.082 \\
\hline [H3K27me3+H3K9me3] & 657,500 & 656,000 & 0.361 & 0.36 & 0.643 & 0.617 \\
\hline$[\mathrm{H} 3 \mathrm{~K} 27 \mathrm{ac}+\mathrm{H} 3 \mathrm{~K} 27 \mathrm{me} 3+\mathrm{H} 3 \mathrm{~K} 9 \mathrm{me}+\mathrm{H} 4 \mathrm{~K} 20 \mathrm{me} 1]$ & 545,000 & 403,500 & 0.299 & 0.222 & 0.792 & 0.379 \\
\hline$[\mathrm{H} 3 \mathrm{~K} 27 \mathrm{ac}+\mathrm{H} 3 \mathrm{~K} 27 \mathrm{me}]$ & 481,000 & 544,500 & 0.264 & 0.299 & 0.096 & 0.089 \\
\hline$[\mathrm{H} 3 \mathrm{~K} 27 \mathrm{ac}+\mathrm{H} 3 \mathrm{~K} 4 \mathrm{me} 3+\mathrm{H} 4 \mathrm{~K} 20 \mathrm{me} 1]$ & 480,000 & 439,000 & 0.264 & 0.241 & 0.053 & 0.05 \\
\hline [H3K4me3+H3K9me3+H4K2Ome1] & 258,000 & 164,500 & 0.142 & 0.09 & 0.098 & 0.06 \\
\hline$[\mathrm{H} 3 \mathrm{~K} 27 \mathrm{ac}+\mathrm{H} 3 \mathrm{~K} 9 \mathrm{me} 3+\mathrm{H} 4 \mathrm{~K} 20 \mathrm{me} 1]$ & 251,000 & 221,000 & 0.138 & 0.121 & 0.238 & 0.072 \\
\hline [H3K27me3+H3K4me3] & 194,500 & 188,500 & 0.107 & 0.104 & 0.031 & 0.022 \\
\hline$[\mathrm{H} 3 \mathrm{~K} 27 \mathrm{ac}+\mathrm{H} 3 \mathrm{~K} 9 \mathrm{me}]$ & 149,000 & 246,000 & 0.082 & 0.135 & 0.034 & 0.038 \\
\hline$[\mathrm{H} 3 \mathrm{~K} 27 \mathrm{ac}+\mathrm{H} 3 \mathrm{~K} 4 \mathrm{me} 3+\mathrm{H} 3 \mathrm{~K} 9 \mathrm{me}]$ & 108,500 & 67,000 & 0.06 & 0.037 & 0.019 & 0.017 \\
\hline$[\mathrm{H} 3 \mathrm{~K} 27 \mathrm{ac}+\mathrm{H} 3 \mathrm{~K} 4 \mathrm{me} 3+\mathrm{H} 3 \mathrm{~K} 9 \mathrm{me} 3+\mathrm{H} 4 \mathrm{~K} 20 \mathrm{me} 1]$ & 109,500 & 76,500 & 0.06 & 0.042 & 0.043 & 0.024 \\
\hline$[\mathrm{H} 3 \mathrm{~K} 27 \mathrm{ac}+$ & 94,500 & 75,000 & 0.052 & 0.041 & 0.154 & 0.086 \\
\hline \multicolumn{7}{|l|}{ H3K27me3+H3K4me3+H3K9me3+H4K20me1] } \\
\hline$[\mathrm{H} 3 \mathrm{~K} 27 \mathrm{ac}+\mathrm{H} 3 \mathrm{~K} 27 \mathrm{me} 3+\mathrm{H} 3 \mathrm{~K} 4 \mathrm{me} 3+\mathrm{H} 4 \mathrm{~K} 20 \mathrm{me} 1]$ & 91,000 & 109,500 & 0.05 & 0.06 & 0.014 & 0.022 \\
\hline [H3K27me3+H3K4me3+H4K2Ome1] & 63,000 & 76,500 & 0.035 & 0.042 & 0.007 & 0.017 \\
\hline [H3K27me3+H3K4me3+H3K9me3+H4K2Ome1] & 55,000 & 28,000 & 0.03 & 0.015 & 0.036 & 0.046 \\
\hline$[\mathrm{H} 3 \mathrm{~K} 27 \mathrm{ac}+\mathrm{H} 3 \mathrm{~K} 27 \mathrm{me} 3+\mathrm{H} 3 \mathrm{~K} 9 \mathrm{me}]$ & 49,000 & 92,500 & 0.027 & 0.051 & 0.017 & 0.026 \\
\hline [H3K27me3+H3K4me3+H3K9me3] & 44,000 & 21,500 & 0.024 & 0.012 & 0.017 & 0.007 \\
\hline$[\mathrm{H} 3 \mathrm{~K} 27 \mathrm{ac}+\mathrm{H} 3 \mathrm{~K} 27 \mathrm{me} 3+\mathrm{H} 3 \mathrm{~K} 4 \mathrm{me} 3]$ & 25,500 & 33,000 & 0.014 & 0.018 & 0.007 & 0.014 \\
\hline$[\mathrm{H} 3 \mathrm{~K} 27 \mathrm{ac}+\mathrm{H} 3 \mathrm{~K} 27 \mathrm{me} 3+\mathrm{H} 3 \mathrm{~K} 4 \mathrm{me} 3+\mathrm{H} 3 \mathrm{~K} 9 \mathrm{me}]$ & 6,500 & 13,500 & 0.004 & 0.007 & 0 & 0 \\
\hline Total & $65,222,000$ & $64,970,500$ & 35.825 & 35.687 & 30.454 & 28.792 \\
\hline
\end{tabular}

underlying biological processes, including parasitic success in RKN. This study provides the first insight of the genome-wide epigenetic landscape of $M$. incognita and its direct relationship to gene transcription. Using ChIP-seq, we first analyzed the distribution of five posttranslational histone modifications. We then investigated the impact of these modifications on chromatin structure and their co-distribution relative to TE-rich regions. Finally, we assessed the influence of the chromatin landscape on gene expression during developmental, with a focus on parasitism genes, such as those encoding effectors.

\section{RESULTS}

\section{The Chromatin Landscape of Five Histone Modifications in $M$. incognita}

We performed ChIP-Seq analysis to study posttranslational histone modifications in M. incognita. We first checked the specificity of a set of commercially available antibodies and optimized the binding and sonication steps. Four out of 15 available antibodies previously used in C. elegans passed the two-step validation process (Cosseau et al., 2009). These antibodies gave single bands on western blots and saturated signals on ChIP-titration (Supplementary Figure S1 and Supplementary Table S1). They were raised specifically against H3K27ac, H4K20me1, H3K9me3 and H3K27me3, and were added to the first previously validated antibody raised against H3K4me3 (Perfus-Barbeoch et al., 2014). ChIP-Seq data were obtained for two RKN developmental stages, eggs and pre-parasitic juveniles 2 (J2s), and were mapped to the most complete annotated $M$. incognita genome publicly available (Blanc-Mathieu et al., 2017). Regions displaying a specific enrichment in histone modifications were identified (Supplementary Figure S2), making study of the chromatin landscape based on these five histone modifications meaningful. 


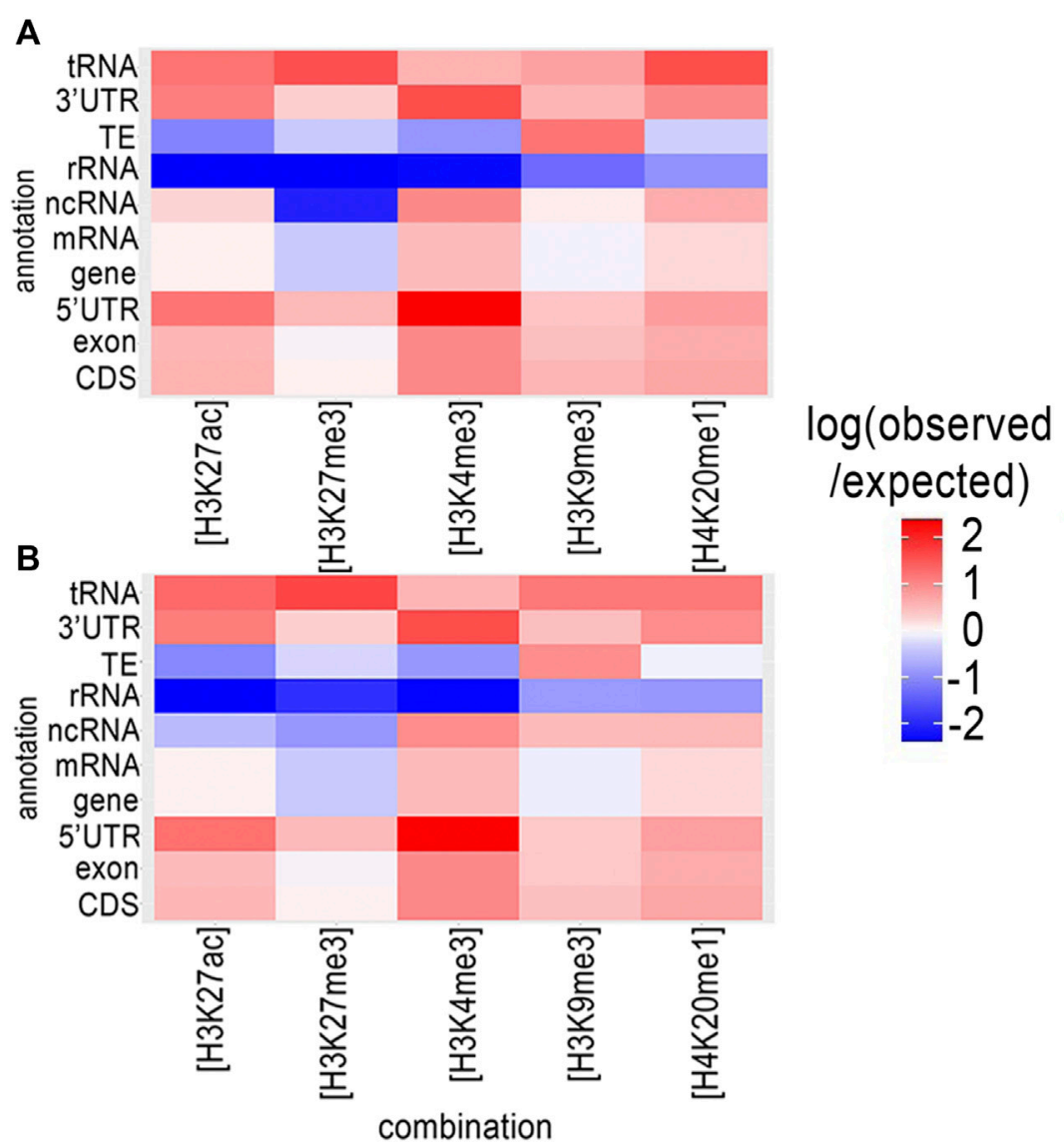

FIGURE 1 | Genome wide distribution of histone modifications in relation to annotations for the $M$. incognita genome. The distribution of histone modifications was analyzed with ChromstaR, which calculated the spatial enrichment in histone modifications for different available genomic annotations in (A) Eggs or (B) J2s. Enrichment is represented as the log (observed/expected) value and ranges from 2.5 (highly enriched, red) to -2.5 (depletion, blue). This enrichment heatmap is a $5 \times 10$ matrix representing five histone modifications (H3K4me3, H3K9me3, H3K27ac, H3K27me3 and H4K20me1) and 10 genomic annotated elements (CDS, exon, five prime UTR, gene, mRNA, ncRNA, rRNA, TE, three prime UTR and tRNA). Three biological replicates of $M$. incognita eggs have been treated jointly to identify common histone modification enrichment.

We investigated the distribution of histone modifications in the $M$. incognita genome further, by calculating the genomic frequencies of each histone modification and of the 31 histone modification combinations detected genome-wide (Table 1). These frequencies correspond to the percentage of the total genome ( $184 \mathrm{Mb}$ divided by a bin size of $500 \mathrm{bp}$ each) covered by each histone modification. In both eggs and J2s, H3K4me3 was the most prevalent histone modification, covering 13.9 and $14.6 \%$ of the genome, respectively. By contrast, H3K9me3, H3K27me3, H4K20me1 and H3K27ac each covered less than $4 \%$ of the genome. Very little difference in the frequencies of these modifications was observed between eggs and J2s (Table 1).

Histone modifications can act together in a combinatorial manner to exert different effects on the genome. The most frequent histone combinations observed in both eggs and $\mathrm{J} 2 \mathrm{~s}$ involved $\mathrm{H} 4 \mathrm{~K} 20 \mathrm{me} 1+\mathrm{H} 3 \mathrm{~K} 27 \mathrm{me} 3$, or $\mathrm{H} 4 \mathrm{~K} 20 \mathrm{me} 1+\mathrm{H} 3 \mathrm{~K} 9 \mathrm{me} 3$, or $\mathrm{H} 4 \mathrm{~K} 20 \mathrm{me} 1+\mathrm{H} 3 \mathrm{~K} 27 \mathrm{me} 3+\mathrm{H} 3 \mathrm{~K} 9 \mathrm{me} 3$, with frequencies ranging between 1.3 and $2 \%$. The other 23 combinations presented relatively low coverage, with a frequency of less than $1 \%$. In total, $\sim 35 \%$ of the $M$. incognita genome was covered by the five histone modifications and their combinations (Table 1). Overall, these results reveal a consistent chromatin landscape during $M$. incognita eggsto-J2s transition based on the five post translational histone modifications considered here.

\section{M. incognita Displays Canonical Distribution for Histone Modifications}

We used ChromstaR (Taudt et al., 2016) to analyze the spatial pattern of statistically significant enrichment in each histone modification associated with different functional genomic elements in M. incognita. These associations provide clues for the functions and regulatory mechanisms of histone modifications. Spatial enrichment was calculated and represented as a heatmap for both eggs and J2s (Figure 1). Enrichment level was calculated for all the available annotations for the $M$. incognita genome: coding sequence (CDS), exon, 5'-untranslated region (UTR), messenger RNA 


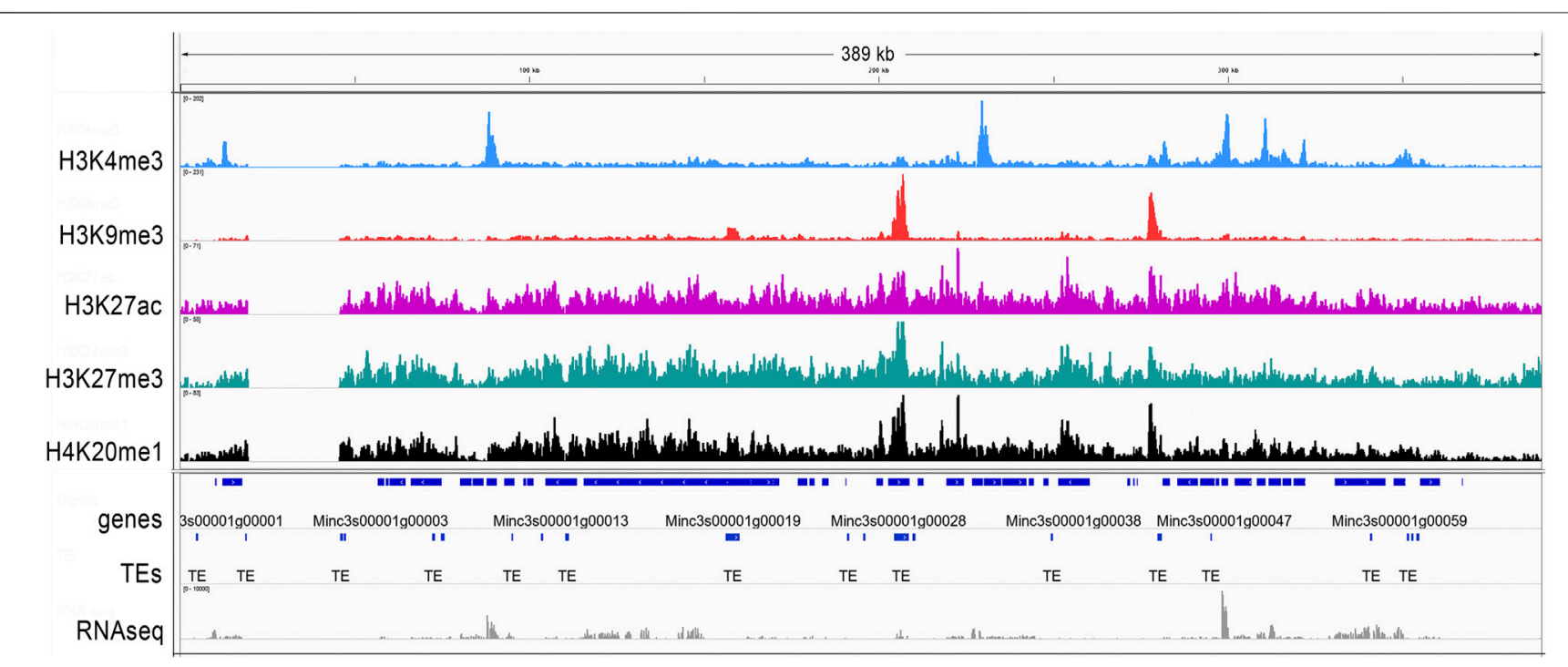

FIGURE 2 | H3K4me3, H3K9me3, H3K27ac, H27me3 and H4K20me1 histone modifications on the M. incognita genome. The general tracks of histone modifications are illustrated on the longest scaffold (Minc3s00001) of the M. incognita genome. Sequence reads for H3K4me3 (blue), H3K9me3 (red), H3K27ac (pink), H3K27me3 (green) and H4K20me1 (black) samples were visualized in IGV software. Values shown on the $y$ axis represent the relative enrichment of ChIP-Seq signals obtained with PeakRanger (peaks correspond to read counts after background/input subtraction). The tracks were overlaid with the $M$. incognita's annotations (dark blue) of Genes and Transposable Elements (TE), as well as RNA-seq reads (grey). Each track contains information from one biological replicate of eggs.

(mRNA), non-coding RNA (ncRNA), ribosomal RNA (rRNA), TE, $3^{\prime}$-UTR and tRNA.

A similar enrichment distribution was observed in both Eggs (Figure 1A and Supplementary Table S2) and J2s (Figure 1B and Supplementary Table S2). We observed a highly significant enrichment in $\mathrm{H} 3 \mathrm{~K} 4 \mathrm{me} 3$ for sequences annotated as related to protein-coding genes (CDS, exon, UTRs and mRNA) and various types of non-protein-coding RNA genes (ncRNA and tRNA), this enrichment being strongest for the $5^{\prime}$-UTR (Heatmap scores $+2,37$ and $+2,36$ for Eggs and J2s, respectively). An enrichment of H3K27me3 was also observed in the $5^{\prime}$-UTR, however the enrichment in this modification was weak for other gene-related annotations. On the contrary, H3K4me3 modifications were less represented in association with rRNA or TE. H3K9me3 enrichment was observed for almost all genomic annotations, particularly for TE (Heatmap scores +1.19 and +0.94 for Eggs and J2s, respectively), but not for rRNA. Interestingly, rRNA genes displayed a relative depletion for all five histone modifications. Finally, the levels of enrichment in $\mathrm{H} 3 \mathrm{~K} 27 \mathrm{ac}, \mathrm{H} 3 \mathrm{~K} 27 \mathrm{me} 3$ and H4K20me1 were highest for tRNA genes.

Histone modifications associated with genomic elements were visualized on the longest scaffold, Minc3s00001, as an example (Figure 2). For H3K4me3, sharp peaks overlapping with the transcriptional start site (TSS/5' -UTR/start) were observed. For $\mathrm{H} 3 \mathrm{~K} 9 \mathrm{me}$, peaks overlapping both protein-coding genes and TEs were observed, whereas H3K27ac, H3K27me3 and H4K20me1 yielded broad shapes and distributions. The distribution and enrichment patterns of histone modifications suggest a canonical role of $\mathrm{H} 3 \mathrm{~K} 9 \mathrm{me} 3$ in TE repression and of $\mathrm{H} 3 \mathrm{~K} 4 \mathrm{me} 3$ in promoting protein-coding gene expression (Supplementary Figure S3).

\section{Transposable Element Orders Display Preferential Enrichment in H3K9me3}

TEs are important drivers of genomic plasticity in $M$. incognita (Kozlowski et al., 2021). The genome-wide annotation of $M$. incognita TEs identified retrotransposons and DNAtransposons, such as terminal inverted repeats (TIR), miniature inverted repeat transposable elements (MITEs), helitrons, maverick elements, long terminal repeats (LTR), long and short interspersed nuclear elements (LINE and SINE), terminal-repeat retrotransposons in miniature (TRIM), and large retrotransposon derivatives (LARD) (Kozlowski et al., 2021). We calculated the frequency of histone modifications associated with TE annotations (Table 1). In both eggs and J2s, H3K9me3 had the highest frequency, covering 8.6 and $7.1 \%$ of annotated TEs, respectively. By contrast, $\mathrm{H} 3 \mathrm{~K} 4 \mathrm{me} 3, \mathrm{H} 4 \mathrm{~K} 20 \mathrm{me} 1, \mathrm{H} 3 \mathrm{~K} 27 \mathrm{me} 3$ and $\mathrm{H} 3 \mathrm{~K} 27 \mathrm{ac}$ had lower frequencies, ranging from 0.3 to $2.9 \%$. Three histone modification combinations, involving H4K20me1, were also present at a high frequency $(1.4-5.9 \%)$ at annotated TEs. The other 23 histone combinations covered less $1 \%$ of the annotated TE. We found that $\mathrm{H} 3 \mathrm{~K} 9 \mathrm{me} 3$ was observed more frequently than expected in association with all TE orders except SINE (Figure 3 and Supplementary Table S2). H4K20me1 modification was observed more frequently in 4 TE orders (TRIM, MITE, TIR and helitron). By contrast, H3K4me3, $\mathrm{H} 3 \mathrm{~K} 27 \mathrm{ac}$ and $\mathrm{H} 3 \mathrm{~K} 27 \mathrm{me} 3$ displayed a lower association with all TE orders. The enrichment of most TE subfamilies in H3K9me3 supports the hypothesis of a role for this histone modification in repressing TE, consistent with conservation of the canonical role of this modification in M. incognita. 


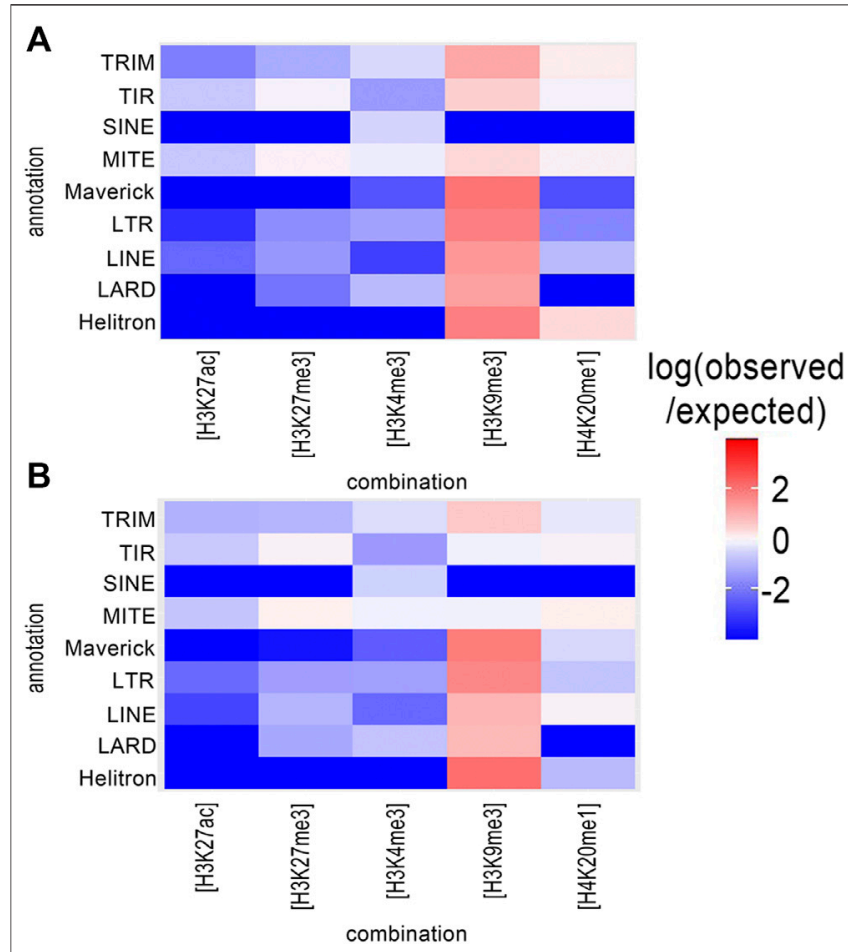

FIGURE 3 | Distribution of histone modifications in relation to transposable element (TE) orders. The distribution of histone modifications was analyzed with ChromstaR, which calculated the spatial enrichment in histone modifications for annotated subfamilies of TE in $M$. incognita (A) Eggs or (B) J2s. Enrichment is represented as the log (observed/expected) value and ranges from +4 (highly enriched, red) to -4 (depletion, blue). This enrichment heatmap is a $5 \times 11$ matrix representing five histone modifications (H3K4me3, H3K9me3, H3K27ac, H3K27me3 and H4K2Ome1) and 11 TE orders (4 DNA-transposons (Helitron, Maverick, TIR, MITE), and five RNA transposons (LINE, LTR, SINE, LARD and TRIM)). Three biological replicates of $M$. incognita eggs have been treated jointly to identify common histone modification enrichment.

\section{The H3K4me3 Modification is Associated With Higher Levels of Gene Expression During Nematode Development}

Histone modifications are known to regulate the spatiotemporal expression of protein-coding genes (Stillman, 2018), and, thus, developmental processes. Early in the development of $M$. incognita, the transition from eggs to J2s constitutes a dramatic change in environment for the nematode, because the mobile J2s are released into the soil after hatching. We evaluated changes in both the pattern of histone modifications and gene expression during this transition, by determining the number of protein-coding genes overlapping each area of enrichment in particular histone modifications and their combinations (Table 2). We found that 13,322 of the 43,718 annotated $M$. incognita protein-coding genes were associated with at least one histone modification in eggs, whereas 23,470 genes were associated with at least one histone modification in J2s. At both developmental stages, H3K4me3 modification was associated with the largest number of genes $(6,014$ in eggs and
10,564 in J2s), followed by H3K9me3, H4K20me1, H3K27me3 and $\mathrm{H} 3 \mathrm{~K} 27 \mathrm{ac}$. The most prevalent histone modification combinations were the $\mathrm{H} 3 \mathrm{~K} 9 \mathrm{me} 3+\mathrm{H} 4 \mathrm{~K} 20 \mathrm{me} 1$ combination in eggs, which was associated with 531 genes, and the $\mathrm{H} 3 \mathrm{~K} 27 \mathrm{me} 3+\mathrm{H} 4 \mathrm{~K} 20 \mathrm{me} 1$ combination in J2s, which was associated with 803 genes.

We then assessed the impact of each histone modification on gene expression (Figure 4). According to ChIP-seq and RNA-seq data, 10,242 genes in eggs and 18,577 genes in J2s were both expressed and associated with at least one histone modification.

The distribution of gene expression values was shifted towards the highest median values for $\mathrm{H} 3 \mathrm{~K} 4 \mathrm{me} 3$, and toward the lowest median values for the histone modifications $\mathrm{H} 3 \mathrm{~K} 9 \mathrm{me} 3$ and H3K27me3 (Figures 4A,B). The other two known histone modifications, $\mathrm{H} 3 \mathrm{~K} 27 \mathrm{ac}$ and $\mathrm{H} 4 \mathrm{~K} 20 \mathrm{mel}$ modifications, were associated with intermediate levels of gene expression (Figures 4A,B). These observations are consistent with observations for $C$. elegans, in which euchromatic regions with active transcription are enriched in $\mathrm{H} 3 \mathrm{~K} 4 \mathrm{me} 3$ and $\mathrm{H} 3 \mathrm{~K} 27 \mathrm{ac}$, whereas regions with low levels of transcription activity are enriched in $\mathrm{H} 3 \mathrm{~K} 9 \mathrm{me} 3$ and H3K27me3 (Bian et al., 2020).

We analyzed the top and bottom $10 \%$ of protein-coding genes ranked according to expression levels, to explore the proximal regulatory elements. We extended the area of overlap considered to $2 \mathrm{~kb}$ upstream and downstream from the protein-coding genes, with ChromstaR (Figure 5). For the top 10\% of expressed genes at both stages, H3K4me3 enrichment overlapped start codon, implying that this histone modification occurs preferentially at the TSS of highly expressed genes (Figures 5A,C). H3K27ac presented a "flat" profile, indicating a lack of evident enrichment. For H3K27me3, H3K9me3 and H4K20me1, the log (expected/ observed) value was below zero, indicating that the most strongly expressed genes were depleted in these histone modifications. By contrast, the enrichment profile of $\mathrm{H} 3 \mathrm{~K} 4 \mathrm{me} 3$ in the $10 \%$ of genes with the lowest levels of expression appeared as a "valley", indicating depletion (Figures 5B,D). The H3K27ac, H3K9me3, $\mathrm{H} 3 \mathrm{~K} 27 \mathrm{me} 3$ and $\mathrm{H} 4 \mathrm{~K} 20 \mathrm{mel}$ signals were flat between and around the genes (Figures 5B,D).

Finally, during the eggs-to-J2s transition, a change in the distribution of $\mathrm{H} 3 \mathrm{~K} 4 \mathrm{me} 3$ was observed, with this modification disappearing from the TSS of underexpressed genes and becoming enriched at the TSS of overexpressed genes. This change in the distribution shows a dynamic in histone modifications. However, it was less straightforward to establish a direct correlation between gene expression levels and the presence/absence of other histone modifications. The pattern of association between histone modifications and annotated protein-coding genes was, therefore, robust only for $\mathrm{H} 3 \mathrm{~K} 4 \mathrm{me} 3$, and was associated with an expression switch during the eggs-to-J2s transition.

\section{Stage-specific Enrichment in GO Terms for Genes Associated With H3K4me3}

Given the strong association of H3K4me3 with the higher expression of protein-coding gene expression, we compared functional annotations in eggs and J2s. We identified 6,014 
TABLE 2 | Distribution of histone modifications in relation to protein-coding genes. Numbers of $M$. incognita's annotated protein-coding genes associated with $\mathrm{H} 3 \mathrm{~K} 4 \mathrm{me}$, H3K9me3, H3K27ac, H3K27me3 and H4K20me1 histone modifications and their combinations, for Egg and J2 samples. Protein-coding genes were considered to be associated with a histone modification if at least $1 \mathrm{bp}$ of the protein-coding gene annotation overlapped with the identified histone modification.

\begin{tabular}{|c|c|c|}
\hline $\begin{array}{l}\text { Histone modifications and } \\
\text { combinations }\end{array}$ & $\begin{array}{c}\text { Associated } \\
\text { genes in eggs }\end{array}$ & $\begin{array}{l}\text { Associated } \\
\text { genes in } \mathrm{J} 2 \mathrm{~s}\end{array}$ \\
\hline H3K4me3 & 6014 & 10564 \\
\hline H3K9me3 & 1762 & 3475 \\
\hline H4K20me1 & 1212 & 2127 \\
\hline H3K27me3 & 829 & 1831 \\
\hline H3K27ac & 756 & 1047 \\
\hline H3K9me3+H4K2Ome1 & 531 & 699 \\
\hline H3K27me3+H3K9me3+H4K2Ome1 & 362 & 571 \\
\hline H3K27me3+H4K2Ome1 & 360 & 803 \\
\hline H3K27ac + H4K20me1 & 250 & 299 \\
\hline H3K4me3+H3K9me3 & 221 & 253 \\
\hline H3K27ac + H3K27me3+H4K2Ome1 & 181 & 400 \\
\hline H3K4me3+H4K2Ome1 & 150 & 221 \\
\hline H3K27ac + H3K4me3 & 138 & 211 \\
\hline H3K27me3+H3K9me3 & 96 & 220 \\
\hline $\mathrm{H} 3 \mathrm{~K} 27 \mathrm{ac}+\mathrm{H} 3 \mathrm{~K} 27 \mathrm{me} 3$ & 93 & 166 \\
\hline H3K27ac + H3K27me3+H3K9me3+H4K2Ome1 & 66 & 92 \\
\hline H3K27ac + H3K4me3+H4K2Ome1 & 57 & 105 \\
\hline H3K4me3+H3K9me3+H4K2Ome1 & 42 & 35 \\
\hline H3K27me3+H3K4me3 & 41 & 66 \\
\hline H3K27ac + H3K9me3+H4K2Ome1 & 40 & 54 \\
\hline H3K27ac + H3K9me3 & 26 & 79 \\
\hline H3K27ac + H3K4me3+H3K9me3+H4K20me1 & 22 & 16 \\
\hline $\mathrm{H} 3 \mathrm{~K} 27 \mathrm{ac}+\mathrm{H} 3 \mathrm{~K} 4 \mathrm{me} 3+\mathrm{H} 3 \mathrm{~K} 9 \mathrm{me} 3$ & 17 & 19 \\
\hline H3K27ac + H3K27me3+H3K4me3+H4K2Ome1 & 14 & 28 \\
\hline $\mathrm{H} 3 \mathrm{~K} 27 \mathrm{ac}+\mathrm{H} 3 \mathrm{~K} 27 \mathrm{me} 3+\mathrm{H} 3 \mathrm{~K} 4 \mathrm{me} 3+\mathrm{H} 3 \mathrm{~K} 9 \mathrm{me} 3+\mathrm{H} 4 \mathrm{~K} 20 \mathrm{me} 1$ & 13 & 22 \\
\hline H3K27ac + H3K27me3+H3K9me3 & 8 & 31 \\
\hline H3K27ac + H3K27me3+H3K4me3 & 7 & 10 \\
\hline H3K27me3+H3K4me3+H4K2Ome1 & 5 & 8 \\
\hline H3K27me3+H3K4me3+H3K9me3+H4K2Ome1 & 4 & 7 \\
\hline H3K27me3+H3K4me3+H3K9me3 & 3 & 4 \\
\hline H3K27ac + H3K27me3+H3K4me3+H3K9me3 & 2 & 7 \\
\hline Total & 13322 & 23470 \\
\hline
\end{tabular}

genes in eggs and 10,564 genes in J2s as associated with $\mathrm{H} 3 \mathrm{~K} 4 \mathrm{me}$. We then annotated the corresponding $M$. incognita proteins thanks to Interproscan (Pratx et al., 2017). Enrichment was detected for $46 \mathrm{GO}$ terms in eggs and $8 \mathrm{GO}$ terms in J2s (Figure 6). GO terms such as "ribonucleoside- and nucleosideassociated processes" were associated with the egg stage, whereas compounds identified in the metabolic processes' ontology such as "ether", "citrate" and "tricarboxylic acid" were specifically enriched in the J2 stage. We also identified 40 GO terms as displaying enrichment at both stages, with the strongest enrichment observed for processes related to protein biosynthesis: "translation," "peptide biosynthetic process," "peptide metabolic process," "amide biosynthetic process," "cellular amide metabolic process" (Figure 6).

Our observations of $\mathrm{H} 3 \mathrm{~K} 4 \mathrm{me} 3$ dynamics during the eggsto-J2s transition led us to analyze the functions of the products of the differentially expressed genes. We identified 89 genes in eggs and 177 genes in J2s as both associated with $\mathrm{H} 3 \mathrm{~K} 4 \mathrm{me} 3$ and differentially expressed. Overrepresentation was detected for $39 \mathrm{GO}$ terms specific to eggs (56/89 genes), and 9 GO terms specific to J2s (28/177 genes). GO terms linked to genomic organization and cell cycleassociated processes were associated with the egg stage, whereas cell signaling, and stimulus responses were specific to the $\mathrm{J} 2$ stage (Figure 7 ).

The identification of orthologs in C. elegans and parasitic nematodes provided insight into the functions of the $\mathrm{H} 3 \mathrm{~K} 4 \mathrm{me} 3$ associated genes differentially expressed during the eggs-to-J2s transition. We found 63 genes in M. incognita eggs and 119 genes in $\mathrm{J} 2 \mathrm{~s}$ for which at least one ortholog was present in C. elegans. Interestingly, orthologs of genes linked to the regulation of histones, DNA metabolism, cytoskeleton organization and the mitotic checkpoint were overrepresented among the most expressed genes in $M$. incognita eggs (Supplementary Table S3). In $M$. incognita J2s, we identified orthologous genes involved in redox status and the regulation of cell trafficking (Supplementary Table S4).

\section{RKN Effector-Coding Genes Are Subject to Regulation by Histone Modifications}

Effectors are secreted proteins that are essentials to nematode parasitism. Studies using RNA-Seq technology provided a comprehensive transcriptome profiling of $M$. incognita effector-producing glands and an opportunity to characterize their different patterns on infective aptitude, from the penetration 


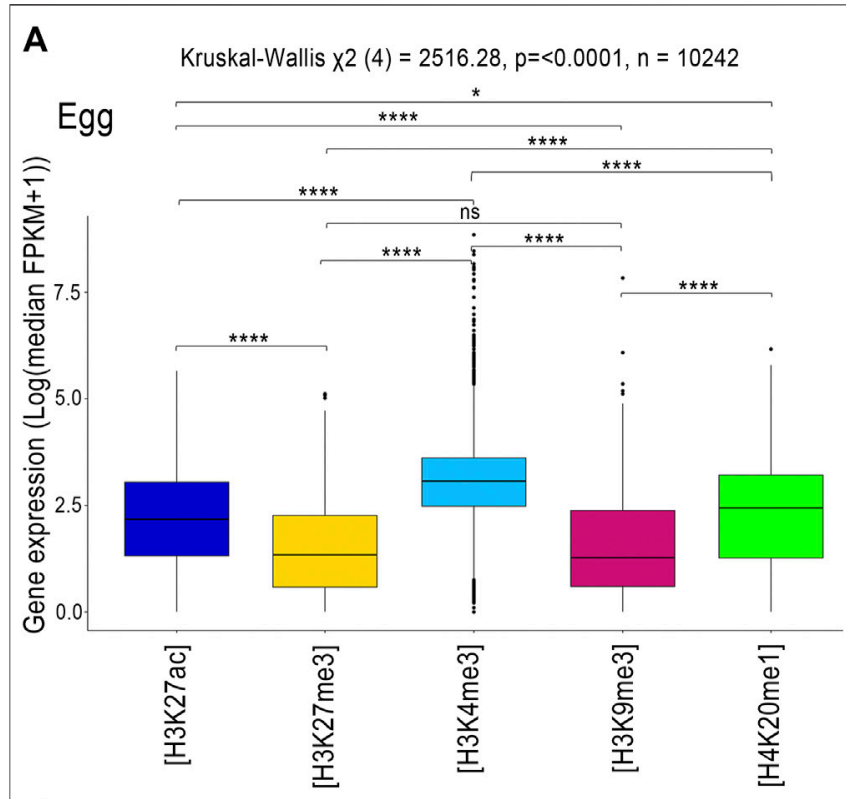

B

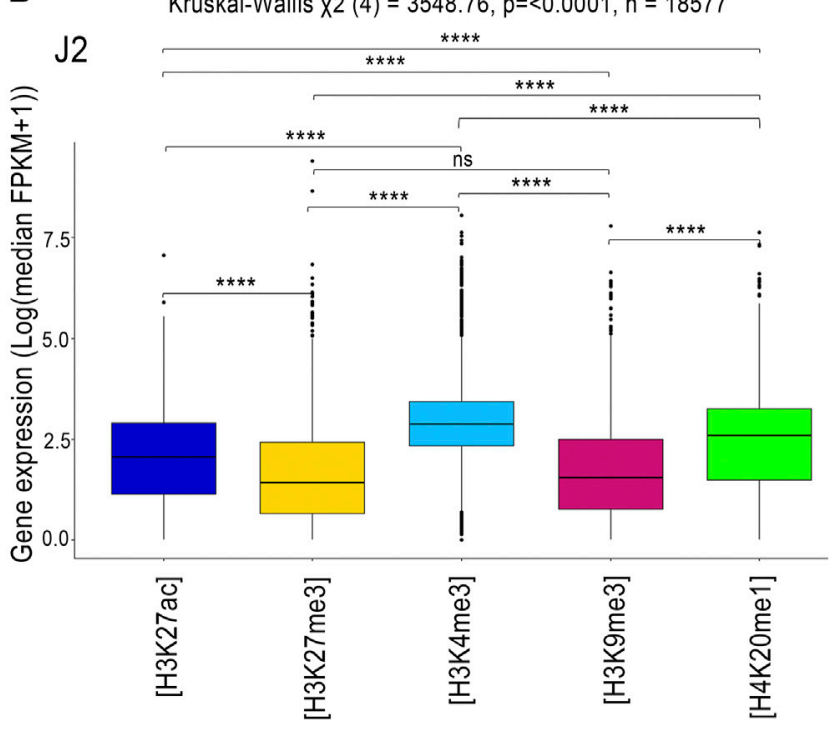

FIGURE 4 | RNA-seq regulation of the protein-coding genes associated with histone modifications. Analysis of transcript levels of the genes associated with H3K27ac (blue), H3K27me3 (yellow), H3K4me3 (sky blue), H3K9me3 (dark pink) and H4K20me1 (green) in (A) Eggs and (B) J2s.

Genes were considered to be associated with a histone modification if at least $1 \mathrm{bp}$ of the annotation overlapped with an identified histone modification. Three biological replicates of $M$. incognita eggs and J2s have been treated jointly to identify common histone modification enrichment using ChromstaR. Normalized expression Log (median FPKM+1) of genes, calculated triplicates is shown. A Kruskal-Wallis test was performed, followed by a pairwise Dunn test, to assess the significance of differences in gene expression level between the five histone modifications. ns $p>0.05,{ }^{\star} p \leq 0.05,{ }^{\star \star} p \leq 0.01,{ }^{\star \star \star} p \leq 0.001$, ${ }^{\star \star \star \star \star} p \leq 0.0001$

to the successful interaction leading to feeding sites and the production of the next generation of eggs (Nguyen et al., 2018; Da Rocha et al., 2021). In M. incognita, subventral glands (SvG) are mostly active during the earliest steps, whereas dorsal gland
(DG) is active in the latest steps of the infection. A total of 48 and 34 putative non-redundant $M$. incognita effectors have been identified in SvG and DG, respectively (Da Rocha et al., 2021). We looked for histone modification associated with effector genes that are overexpressed in J2s (Tables 3, 4 and Supplementary Tables S5, S6). Among the 48 SvG effectors, 14 were associated with both a histone modification dynamic and a differential expression pattern during eggs-to-J2s transition. Only two of those effectors, Mi-GSTS1 and msp2, showed an appearance of activating histone modification in J2s. In contrast, combinations of histone modifications involving the repressive modifications $\mathrm{H} 3 \mathrm{~K} 27 \mathrm{me} 3$ and $\mathrm{H} 3 \mathrm{~K} 9 \mathrm{me} 3$ appeared to be the most abundant in this class of effectors (effector number 6, 8, 10, 13, 14, 23, 24, 29, 33, 37 and 48; Table 3 and Supplementary Table S5). Among the 34 DG effectors, 4 were associated with both a histone modification dynamic and a differential expression pattern during eggs-to-J2s transition. All of them were associated with combinations of repressive histone modifications (Table 4 and Supplementary Table S6). Interestingly, the Mi-14-3-3-b DG effector exhibits reverse dynamics during the transition from eggs to J2s with a repression of expression in J2s associated with the appearance of $\mathrm{H} 3 \mathrm{~K} 27 \mathrm{me} 3$. Altogether, these results suggest that histone modifications act as crucial regulators to precisely produce some effectors in a dose manner and in temporal sequence during parasitism.

\section{DISCUSSION}

Many biological processes involve chromatin changes, including the delimitation of functional elements in the genome and transcription regulation, particularly during complex parasitic life cycles. The RKN $M$. incognita has a wide host range and is found worldwide. Despite its clonal reproduction, $M$. incognita can rapidly adapt to unfavorable conditions (Castagnone-Sereno and Danchin, 2014; Koutsovoulos et al., 2020). Epigenetic mechanisms may contribute to this rapid adaptation and the parasitic success of this nematode. Cytosine methylation is absent or present at only very low levels, in the M. incognita genome, which contains no genes encoding DNA methyltransferases (Perfus-Barbeoch et al., 2014; Pratx et al., 2017). Conversely, histone (de)acetylation and (de)methylation enzymes are present and conserved in the genome of M. incognita (Pratx et al., 2017). However, the role of histone modifications in phytoparasitic nematode biology remains unknown. We deciphered the chromatin landscape in the RKN $M$. incognita by studying five histone modifications and analyzing their dynamics during development. These modifications were not randomly distributed in $M$. incognita and colocalized with genomic elements, forming specific epigenetic signatures.

In the model nematode C. elegans, $\mathrm{H} 3 \mathrm{~K} 4 \mathrm{me} 3$ enrichment is observed in actively expressed regions and therefore associated with euchromatin. By contrast, H3K9me3 and H3K27me3 enrichment is observed in silent genes, transposons, and other repetitive sequences and as such associated with heterochromatic regions. This histone code is observed in most organisms (Barski et al., 2007; Ahringer and Gasser, 2018). However, these histone 

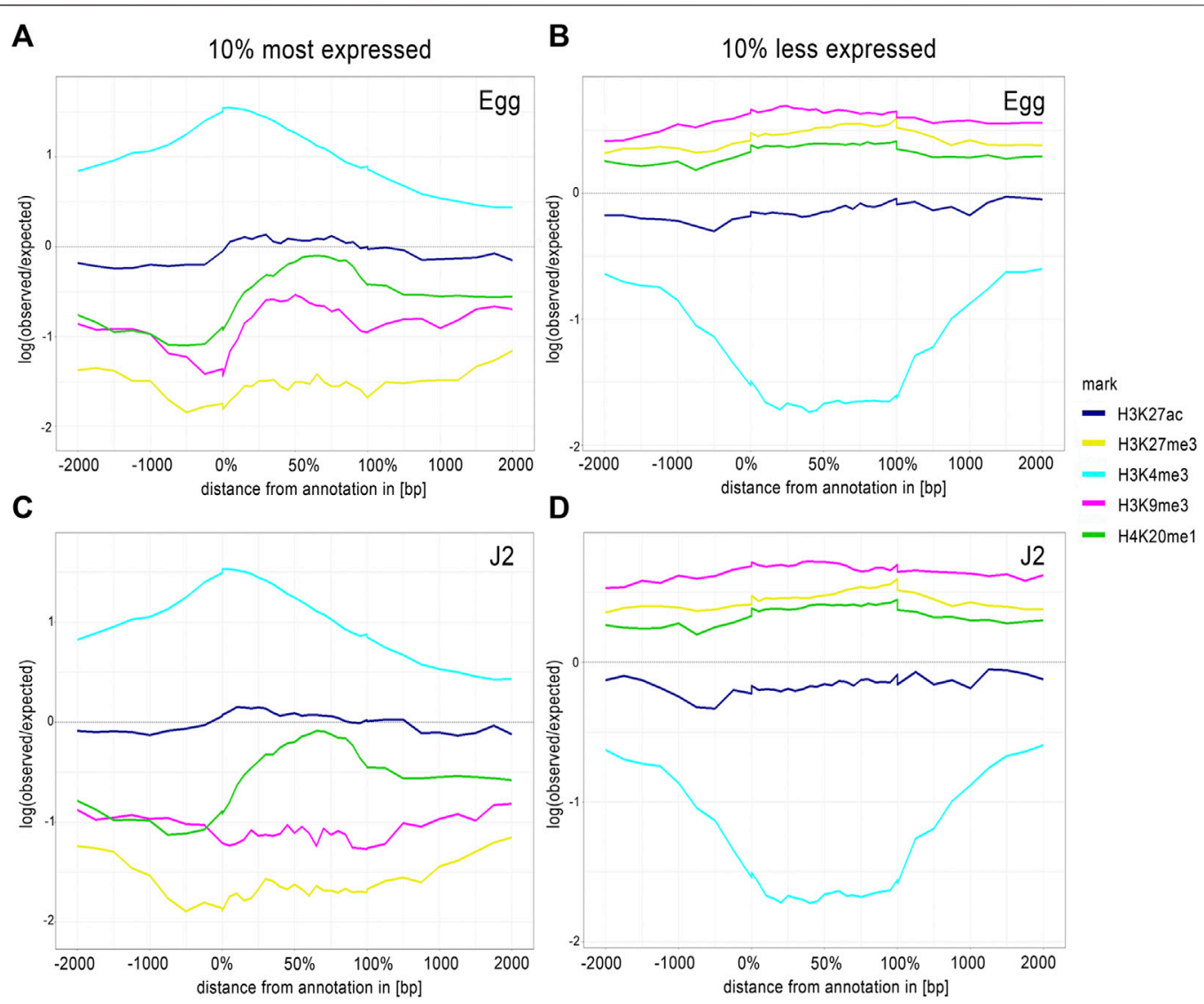

FIGURE 5 | Average H3K4me3 enrichment profiles correlate with TSS regions of 10\% most expressed genes. Average enrichment profiles of five histone modifications along a $4 \mathrm{~kb}$ region framing expressed protein-coding genes after ChIP-Seq of (A, B) eggs and (B, D) J2s. Average enrichment profiles were generated by ChromstaR, [log (observed/expected) value ranging from 1 (highly enriched) to -2 (depletion)], for five histone modifications: H3K27ac (blue), H3K27me3 (yellow), H3K4me3 (sky blue), H3K9me3 (dark pink) and H4K20me1 (green). Three biological replicates of $M$. incognita eggs and J2s have been treated jointly to identify common histone modification enrichment. Enrichment was analyzed for the (A, C) top and (B, D) bottom $10 \%$ of associated protein-coding genes ranked on the basis of RNA-seq normalized expression data Log (median FPKM+1). $x$-axis: \% in gene bodies and distance in bp upstream of TSS or downstream of TES. $y$-axis: Density of mapped reads log (observed/expected)

modifications do not have the same biological implications in some organisms (Garcia et al., 2007). H3K4me3 activates gene expression by a charge-mediated decompaction of the chromatin at promoter sequences (Tessarz and Kouzarides, 2014). H3K4me3 is usually distinguished by sharp peaks or enrichment around the TSS (Lin et al., 2015). In M. incognita, we observed a typical profile of this type, with the sharp H3K4me3 peaks overlapping with the TSS of annotated protein-coding genes, associated with higher levels of gene expression. The conservation of the canonical function of $\mathrm{H} 3 \mathrm{~K} 4 \mathrm{me} 3$ in $M$. incognita will pave the way for deciphering transcriptional regulation during development and parasitism.

Another activating histone modification, H4K20me1, typically results in diffuse chromatin modifications (Zang et al., 2009). In M. incognita, H4K20me1 displayed a diffuse profile of this type over the entire genome and was associated with higher levels of expression than the repressive histone modifications. H4K20me1 levels have been shown to change dynamically during the cell cycle, peaking during the G2/M phase (Oda et al., 2009). At the whole-organism scale, dynamic changes in H4K20 methylation have been observed during mouse preimplantation development, with this modification playing a key role in the maintenance of genome integrity (Shikata et al., 2020). M. incognita seems to have the same histone modification machinery as model organisms, and we can, therefore, predict analogous functions for H4K20me1 in cell cycle regulation and the maintenance of genome integrity in this nematode.

Another well-described histone modification is the heterochromatin-associated modification H3K9me3 (Lachner et al., 2001), which plays an important role in regulating gene expression (Ninova et al., 2019) and is characterized by distinct peaks at protein-coding genes (He et al., 2019). H3K9me3 is also associated with TEs, which require controlled repression to prevent chaotic transposition in the genome. This modification has been described as the principal regulator of these elements in mouse embryonic stem cells (He et al., 2019) and in C. elegans (Ahringer and Gasser, 2018). In M. incognita, H3K9me3 presented sharp peaks in the bodies of genes with low levels of expression relative to other histone modifications. Moreover, the majority of $\mathrm{H} 3 \mathrm{~K} 9 \mathrm{me} 3$ modifications were found on annotated 


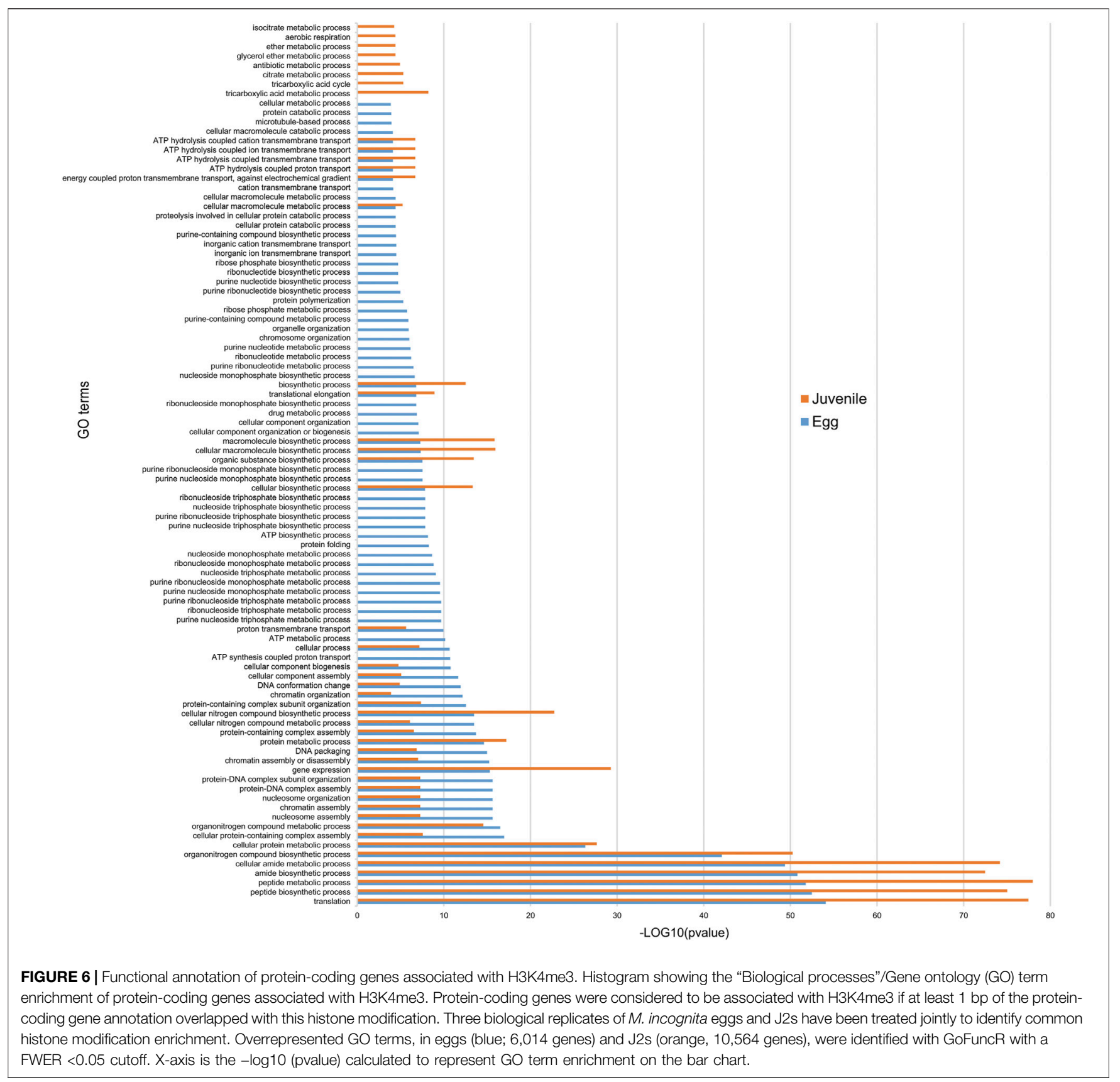

TE, suggesting that $\mathrm{H} 3 \mathrm{~K} 9 \mathrm{me} 3$ represses the mobile elements of the genome and indicating that its canonical function is also conserved in M. incognita.

Different sets of histone modifications can account for gene expression (Dong and Weng, 2013). For instance, a balance between H3K27 trimethylation and H3K27 acetylation has been shown to regulate gene expression in a dynamic manner (Tie et al., 2009). H3K27me3 is a broadly distributed repressive histone modification that downregulates gene expression, as demonstrated during development and cell differentiation (Boyer et al., 2006; Bracken, 2006). By contrast, H3K27ac is an activating histone modification that may be broadly distributed (Battle et al., 2019) or display narrow peaks (Ngo et al., 2019). In M. incognita, H3K27me3 and H3K27ac were broadly distributed throughout the genome despite their dual effects. H3K27ac is usually found on enhancers and can be used to distinguish between active and poised enhancers (Zhang et al., 2020). H3K27ac was associated with genes displaying higher levels of expression than those associated with repressive modifications in $M$. incognita. As in mammals, studies of H3K27ac enrichment could potentially be used to predict enhancers in $M$. incognita on the basis of local chromatin structure. Other sets of histone modifications may fine-tune regulation of the chromatin landscape, but their identification 


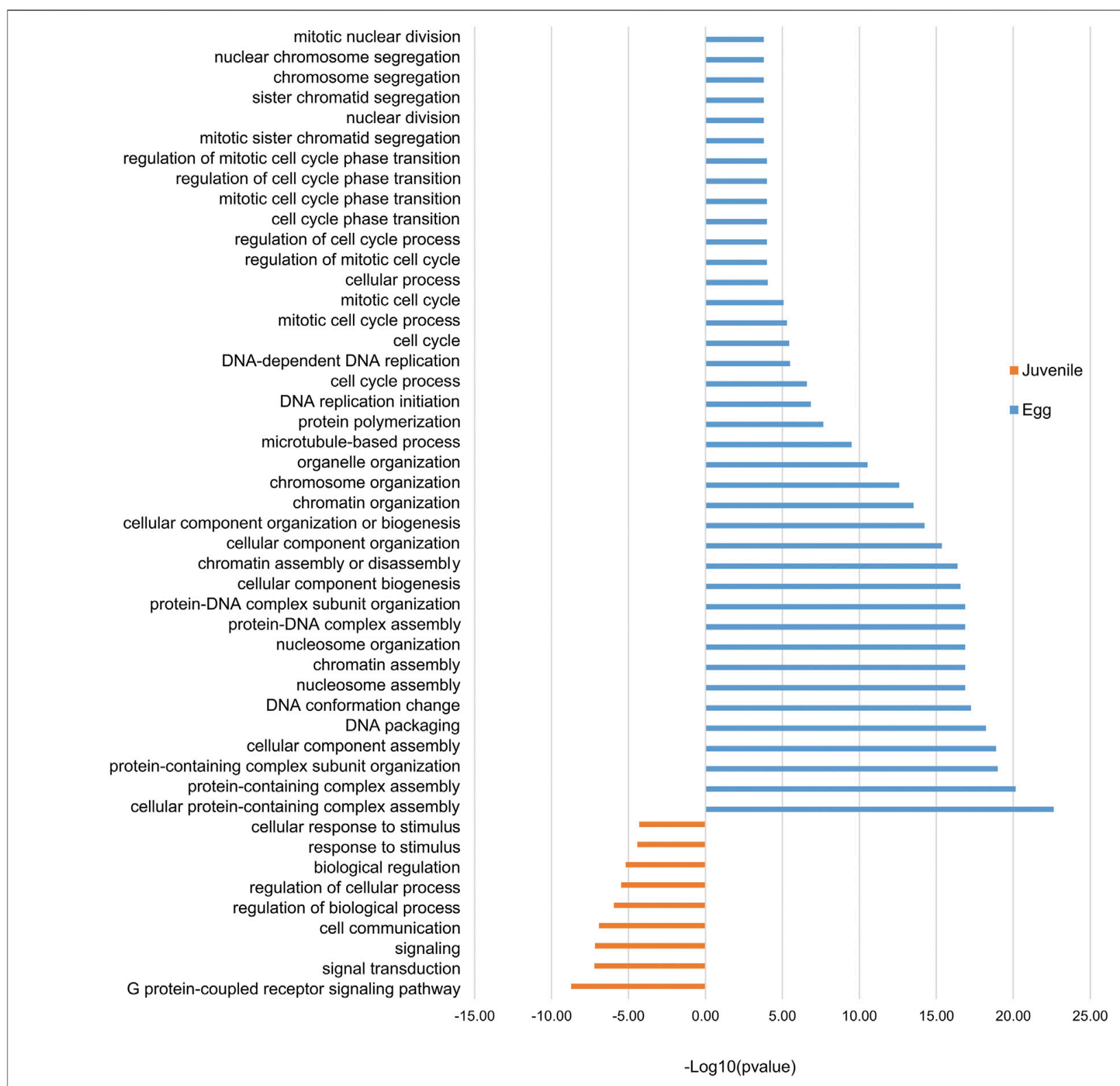

FIGURE 7 | Stage-specific enrichment in Gene Ontology (GO) terms for protein-coding genes associated with H3K4me3. Histogram showing the "Biological processes"/GO term enrichment of protein-coding genes showing both 1) differential gene expression during eggs-to-J2s transition; and 2) H3K4me3 association. Differential gene expression was calculated using DESeq2 on triplicates, with a $p$ value $<0.05$ as a threshold for overexpression. Protein-coding genes were considered to be associated with $\mathrm{H} 3 \mathrm{~K} 4 \mathrm{me} 3$ if at least $1 \mathrm{bp}$ of the protein-coding gene annotation overlapped with this histone modification. Three biological replicates of $M$. incognita eggs and J2s have been treated jointly to identify common histone modification enrichment. Overrepresented GO terms, in eggs (blue; 89 genes) and J2s (orange, 117 genes), were identified with GoFuncR. with a FWER $<0.05$ cutoff. X-axis is the -log10 (pvalue) calculated to represent GO term enrichment on the bar chart.

was limited by antibody availability and specificity in $M$. incognita.

Different combinations of histone modifications can be colocalized, acting together as activators, repressors or in a bivalent manner (Li et al., 2018). For instance, gene expression levels have been shown to be regulated by the ratio of $\mathrm{H} 3 \mathrm{~K} 27 \mathrm{Me} 3$ to $\mathrm{H} 3 \mathrm{~K} 4 \mathrm{Me} 3$ modifications, leading to a bivalent outcome: repression or activation ( $\mathrm{Li}$ et al., 2018). In $M$. incognita, $\mathrm{H} 3 \mathrm{~K} 27 \mathrm{me} 3$ enrichment was observed at the $5^{\prime} \mathrm{UTR}$, potentially accounting for the low levels of expression for the associated genes. The colocalization of $\mathrm{H} 3 \mathrm{~K} 27 \mathrm{me} 3$ and $\mathrm{H} 3 \mathrm{~K} 4 \mathrm{me} 3$ at the $5^{\prime}$ UTR suggests bivalency for these two modifications in $M$. incognita. H3K27me3 enrichment was also found within tRNA-genes, suggesting a role for this modification in tRNA regulation, consistent with the presence of $\mathrm{H} 3 \mathrm{~K} 27 \mathrm{me} 3$ near the RNA polymerase III binding sites used for the synthesis of tRNA in human embryonic stem cells (Alla and Cairns, 2014).

Our findings indicate that histone modification is conserved in $M$. incognita and defines a reproducible and consistent landscape. We therefore further investigated the dynamics of histone 
TABLE 3 | Transcriptional regulation of known subventral glands (SvG) effector genes. According to the literature (Da Rocha et al., 2021 ), 48 non-redundant $M$. incognita effectors have been identified in SvG (i.e., columns: effector-gene number, gene name and accession number on M. incognita genome). For this study, SvG effector genes were classified according to both their expression level and flanking histone modifications during eggs-to-J2s transition. Differential gene expression is shown as RNAseq fold expression changes, Log2 (Fold Change), calculated using DESeq2 on triplicates, with a $p$ value $<0.05$ as a threshold for overexpression. Effector genes were considered to be associated with a histone modification if at least $1 \mathrm{bp}$ of the annotation overlapped with an identified histone modification. Three biological replicates of M. incognita eggs and J2s have been treated jointly to identify common histone modification enrichment using ChromstaR. [] indicates no histone modification has been identified. Full table of known subventral glands (SvG) effector genes can be found as Supplementary Table S5.

\begin{tabular}{|c|c|c|c|c|c|}
\hline $\begin{array}{l}\text { Gene } \\
\text { numbers } \\
\text { according to } \\
\text { Da Rocha } \\
\text { et al., } 2021\end{array}$ & $\begin{array}{c}\text { Gene names } \\
\text { according to } \\
\text { literature }\end{array}$ & $\begin{array}{c}\text { Log2(Fold- } \\
\text { change } \\
\text { J2s/Eggs) }\end{array}$ & Gene & HPTM_eggs & HPTM_J2s \\
\hline
\end{tabular}

Effector genes associated with a differential expression level during eggs-to-J2s transition

\begin{tabular}{|c|c|c|c|c|c|}
\hline 7 & 31H06 (msp22) & 3.57 & Minc3s00376g11251 & {[]} & [] \\
\hline 47 & SXP-RAL2 = Mi-SXP-1 & 4.08 & Minc3s00381g11354 & [] & [] \\
\hline 27 & Mi-PG1 & 5.59 & Minc3s00007g00481 & {[} & [] \\
\hline 2 & 2B02B (Mi-PEL2) & 6.12 & Minc3s00094g04359 & 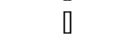 & {[]} \\
\hline 26 & Mi-PEL2 & 6.40 & Minc3s00566g14364 & {[} & [] \\
\hline 35 & Minc03325 & 7.55 & Minc3s00020g01295 & ] & [] \\
\hline 21 & $\begin{array}{l}\text { CL5Contig2_1-EST } \\
\text { (Sec-2) }\end{array}$ & 2.30 & Minc3s00113g04971 & [H3K4me3] & [H3K4me3] \\
\hline 33 & Minc01696 & 4.48 & Minc3s00036g02098 & [H3K9me3] & [H3K9me3] \\
\hline
\end{tabular}

Effector genes associated with both a histone modification dynamic and a differential expression level during eggs-to-J2s transition

\begin{tabular}{|c|c|c|c|c|c|}
\hline 25 & Mi-GSTS1 & 2.14 & Minc3s00365g11068 & [] & [H3K4me3] \\
\hline 6 & 30H07 (msp20) & 2.95 & Minc3s05190g37766 & [] & $\begin{array}{c}{[\mathrm{H} 3 \mathrm{~K} 27 \mathrm{ac}+} \\
\mathrm{H} 3 \mathrm{~K} 27 \mathrm{me} 3+\mathrm{H} 4 \mathrm{~K} 20 \mathrm{me} 1]\end{array}$ \\
\hline 13 & 8D05 (msp9) & 3.20 & Minc3s01244g22037 & [] & [H3K9me3] \\
\hline 18 & CL312Contig1_1-EST & 3.90 & Minc3s00070g03486 & {$[\mathrm{H} 3 \mathrm{~K} 4 \mathrm{me} 3+\mathrm{H} 4 \mathrm{~K} 20 \mathrm{me} 1]$} & [H3K4me3] \\
\hline 3 & 2G02 (msp2) & 3.96 & Minc3s00855g18130 & [] & [H4K2Ome1] \\
\hline 14 & 8E08B (Eng4) & 5.04 & Minc3s00139g05823 & [] & [H3K9me3] \\
\hline 48 & Mi-PEL1 & 6.09 & Minc3s00441g12378 & {[} & [H3K27me3] \\
\hline 8 & 34C04 (Mi-PL1) & 6.14 & Minc3s01107g20785 & [H4K20me1] & [H3K27me3] \\
\hline 29 & Mi-VAP2 & 6.33 & Minc3s01051g20218 & [ & $\begin{array}{c}{[\mathrm{H} 3 \mathrm{~K} 27 \mathrm{ac}+} \\
\mathrm{H} 3 \mathrm{~K} 27 \mathrm{me} 3+\mathrm{H} 4 \mathrm{~K} 20 \mathrm{me1}]\end{array}$ \\
\hline 23 & Mi-CBP1 (42G06) & 6.51 & Minc3s00139g05824 & [H3K27me3] & [H3K9me3] \\
\hline 43 & Minc13292 & 6.99 & Minc3s00083g03979 & [H3K9me3] & [] \\
\hline 10 & 5A12B (ENG1, ENG3) & 8.51 & Minc3s03138g32920 & ] & $\begin{array}{c}{[\mathrm{H} 3 \mathrm{~K} 27 \mathrm{ac}+} \\
\mathrm{H} 3 \mathrm{~K} 27 \mathrm{me} 3+\mathrm{H} 4 \mathrm{~K} 20 \mathrm{me1}]\end{array}$ \\
\hline 24 & Mi-ENG1 (1C11B) & 8.53 & Minc3s03136g32914 & {[} & [H3K27me3+H4K20me1] \\
\hline 37 & Minc03866 & 8.67 & Minc3s00066g03327 & [H3K27me3+H3K9me3+H4K2Ome1] & {$[\mathrm{H} 3 \mathrm{~K} 9 \mathrm{me}]$} \\
\hline
\end{tabular}

TABLE 4 | Transcriptional regulation of known dorsal gland (DG) effector genes. According to the literature (Da Rocha et al., 2021 ), 34 non-redundant $M$. incognita effectors have been identified in DG (i.e., columns: effector-gene number, gene name and accession number on $M$. incognita genome). For this study, DG effector genes were classified according to both their expression level and flanking histone modifications during eggs-to-J2s transition. Differential gene expression is shown as RNA-seq fold expression changes, Log2 (Fold Change), calculated using DESeq2 on triplicates, with a $p$ value $<0.05$ as a threshold for overexpression. Effector genes were considered to be associated with a histone modification if at least $1 \mathrm{bp}$ of the annotation overlapped with an identified histone modification. Three biological replicates of $M$. incognita eggs and J2s have been treated jointly to identify common histone modification enrichment using ChromstaR. [ indicates no histone modification has been identified. Full table of known subventral glands (SvG) effector genes can be found as Supplementary Table S6.

\begin{tabular}{|c|c|c|c|c|c|}
\hline $\begin{array}{l}\text { Gene numbers } \\
\text { according to } \\
\text { Da Rocha } \\
\text { et al., } 2021\end{array}$ & $\begin{array}{c}\text { Gene names } \\
\text { according to } \\
\text { literature }\end{array}$ & $\begin{array}{c}\text { Log2(Fold-change } \\
\text { J2s/Eggs) }\end{array}$ & Gene & HPTM_eggs & HPTM_J2s \\
\hline
\end{tabular}

Effector genes associated with a differential expression level during eggs-to-J2s transition

$\left.\begin{array}{lllll}28 & \text { Minc12639 } & 3.18 & \text { Minc3s00340g10545 } & {[} \\ 25 & \text { Minc01595 } & 3.90 & \text { Minc3s01184g21493 } & {[H 3 K 27 m e 3+H 4 K 20 m e 1]} \\ {[H 3 K 27 m e 3+H 4 K 20 m e 1]}\end{array}\right]$

Effector genes associated with both a histone modification dynamic and a differential expression level during eggs-to-J2s transition

\begin{tabular}{|c|c|c|c|c|c|}
\hline 12 & 34F06 (msp24) & 2.68 & Minc3s00321g10151 & [H3K27me3] & [H3K27me3+H3K9me3] \\
\hline 26 & Minc02097 (35A02, msp25) & 4.80 & Minc3s00202g07465 & ] & [H3K27me3] \\
\hline 9 & 25B10 (msp33) & 4.99 & Minc3s03649g34419 & 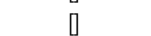 & [H3K9me3] \\
\hline 16 & 6F06 (msp4) & 5.65 & Minc3s02324g29465 & [H3K9me3] & [ \\
\hline 23 & Mi-14-3-3 & -3.43 & Minc3s00122g05244 & ] & [H3K27me3] \\
\hline
\end{tabular}


modifications during development and parasitism, by considering the egg and juvenile stages. This developmental transition constitutes a major change in the nematode environment. J2s hatch and are released into the soil, in which they begin their life as mobile entities, moving towards the plant roots. The soil is a radically different environment from the eggs, and the newly hatched J2s must therefore adapt very rapidly to this new environment. At the scale of the genome, we found that the histone modification profile and gene expression level remained relatively stable during development. However, dynamical changes were highlighted during the eggs-to-J2s transition in $M$. incognita, in analyses at gene level. We identified pathways relating to the cell cycle as overrepresented in eggs, promoting $M$. incognita development. By contrast, J2s presented pathways linked to stimulus responses, reflecting the needs of J2s following their release into the soil after hatching, consistent with previous observations (Da Rocha et al., 2021). Furthermore, based on C. elegans orthology, egg stage-specific genes were involved in cell division, whereas J2s-specific genes were mainly involved in redox status regulation, reflecting the environment shift during the $M$. incognita life cycle. The identification of such candidate genes in $M$. incognita highlights the involvement of histone modifications in nematode development and could lead to the identification of new targets for pest control.

Histone modifications also contribute to the parasitic success of many animal or plant parasites. Parasites possess an arsenal of molecules known as effectors, which promote infection success. Fungal species, such as Fusarium graminearum or Leptosphaeria maculans, are the principal plant-parasitic organisms displaying chromatin-based control of concerted effector gene expression at specific times during infection (Connolly et al., 2013; Soyer et al., 2015). In Zymoseptoria tritici, the H3K27me3 distribution dictates effector gene expression during host colonization, preventing the expression of these genes when not required (Meile et al., 2020).

The association of J2s-overexpressed effector-coding genes with histone modifications suggests that epigenetic regulation contributes to $M$. incognita parasitism. However, by contrast to what we observed for stage-specific genes, the overexpression of effectors in J2s was not associated with $\mathrm{H} 3 \mathrm{~K} 4 \mathrm{me} 3$, whatever the secretory gland, SvG and DG. For effectors, overexpression in J2s is mainly associated with combinations of repressive histone modifications. The overexpression of effector-coding genes needed at a specific time point, such as cell wall degrading enzymes during juvenile stage which help to the penetration of the nematode into the root system, may be under strong and complex regulation. In that respect, having effector-coding genes under repressive histone modifications could help the nematode to fine-tune their expression in a spatio-temporal way during plant infection. For instance, different histone modification dynamics may account for the coordinated, yet slightly different, expression of 2 pectate lyase genes, Mi-pel-1, and Mi-pel-2, during $M$. incognita infection of roots. Indeed, while these 2 genes were both overexpressed in early J2s stage (with similar fold-changes), only Mi-pel-1 gene was associated with repressive $\mathrm{H} 3 \mathrm{~K} 27 \mathrm{me}$. Potential release of this repressive histone modification may provide an explanation for the expression of Mi-pel-1 only at late J2s stage, as previously reported (Huang et al., 2005).

Another example is the Mi-14-3-3-b DG effector gene which was the only one overexpressed in eggs and showing appearance of an $\mathrm{H} 3 \mathrm{~K} 27$ me 3 modification during the eggs-toJ2s transition. This result correlates with what is already known about the expression pattern of Mi-14-3-3-b during $M$. incognita infection with an early expression in eggs, a strong repression in $\mathrm{J} 2 \mathrm{~s}$ and a late expression in the female stage (Sacco et al., 2009).

More generally, these results suggest that the fine-tuning of effector production during parasitism could be achieved through either another activating histone modification, still to be studied, or a different process such as transcription factors (TFs) activation. Consistent with this, a putative cisregulatory element "Mel-DOG" has been identified in $M$. incognita DG effector promoters (Da Rocha et al., 2021). This might be the missing activator switch for the expression of DG effector genes at specific stages during the lifecycle of the nematode, even if the associated TFs are yet to be discovered. To achieve precise and accurate regulation of effector-genes, TFs and histones modifications may work in a cooperative way.

We describe here the chromatin landscape of a parasitic nematode, revealing a dynamic process during the life cycle. This pioneering study shows that $M$. incognita presents a histone modification similar to that of the model nematode $C$. elegans. Beyond model organisms, the epigenome arguably plays an important role in development and the regulation of parasitism. The next step will be to decipher the epigenetic response of $M$. incognita to environmental changes, such as host adaptation, in greater detail.

\section{MATERIALS AND METHODS}

\section{Biological Materials}

One-month-old tomato plants, Solanum lycopersicum (St Pierre), were inoculated with soil infested with $M$. incognita. Eggs were collected from tomato roots seven-week-old after infection, by grinding, sterilizing, and filtering, as previously described (Caillaud and Favery, 2016). Extracted eggs were purified by centrifugation on a $30 \%$ sucrose gradient, washed and either stored at $-80^{\circ} \mathrm{C}$ for subsequent experiments or kept in autoclaved tap water, at room temperature, for 7 days, to produce juveniles J2s. Hatched J2s were collected by filtration and centrifugation $(13,000 \times \mathrm{g}, 1 \mathrm{~min})$ and stored at $-80^{\circ} \mathrm{C}$.

\section{Antibody Screening}

Commercially available antibodies raised against histones with posttranslational modifications were selected on the basis of two criteria: ChIP-grade and preferentially used in the model nematode C. elegans (Supplementary Table S1). We assessed the specificity of each antibody in $M$. incognita by a two-step method combining western blotting and ChIP-titration, as described by Cosseau (Cosseau et al., 2009). 


\section{Western Blot}

Nematodes were resuspended in a homemade extraction buffer (3\% SDS, 10\% sucrose, $0.2 \mathrm{M} \mathrm{DTT,} 1.25 \mathrm{mM}$ sodium butyrate, and $62.5 \mathrm{M}$ Tris/Cl $\mathrm{pH} 6.8$ ) and crushed with a glass Dounce homogenizer for $2 \mathrm{~min}$. Samples were sonicated (Vibra Cell ${ }^{\mathrm{TM}}$ ) three times, at $70 \%$ intensity, for $15 \mathrm{~s}$ each, with cooling on ice during the intervals. They were then boiled for $5 \mathrm{~min}$ at $99^{\circ} \mathrm{C}$ after the addition of Laemmli buffer (Cat. \#1410737, Biorad). Proteins were separated by SDS-PAGE and transferred to a membrane with a Trans Blot TURBO (Biorad). The membrane was incubated for $1 \mathrm{~h}$ at $37^{\circ} \mathrm{C}$ in a homemade blocking buffer (50 mM NaCl, 0.05\% Tween 20,5\% fat-free dry milk, $20 \mathrm{mM}$ Tris/Cl pH 7) and then for $1.5 \mathrm{~h}$ with antibodies in the blocking buffer. Finally, the membrane was washed and incubated with a secondary antibody. Signals were detected by incubation with SuperSignal West Pico Chemiluminescent Substrate (Thermo Fisher Scientific, Cat.34579) and to the use of ChemiDoc Imaging systems (Biorad). Antibodies that did not bind to a unique target were discarded from the analysis (Supplementary Table S1 and Supplementary Figure S1).

\section{Crosslinking and Chromatin Immunoprecipitation}

Frozen eggs or juveniles were resuspended in $500 \mu \mathrm{L}$ Hank's balanced salt solution (HBSS, Sigma-Aldrich, Cat. \#H4641, Lot RNBG 1861) and crushed with a glass Dounce homogenizer for $7 \mathrm{~min}$. We then added $500 \mu \mathrm{L} 1 \times$ HBSS and transferred the solution to an Eppendorf tube. Samples were centrifuged (at 2,700 $\times \mathrm{g}, 5 \mathrm{~min}, 4^{\circ} \mathrm{C}$ ). For crosslinking, the pellet was resuspended in $1 \mathrm{ml} 1 \times$ HBSS containing $13.5 \mu \mathrm{L}$ of $37 \%$ formaldehyde (SigmaAldrich, Cat. \#252549), and incubated for $10 \mathrm{~min}$ at room temperature, with occasional inversion. Binding was stopped by adding $57 \mu \mathrm{L} 2 \mathrm{M}$ glycine (Diagenode, cat. C01011000) and incubating the sample for $5 \mathrm{~min}$ at room temperature. Samples were centrifuged at $2,700 \times \mathrm{g}, 4^{\circ} \mathrm{C}$ for $5 \mathrm{~min}$. The pellet was rinsed twice, with $1 \mathrm{ml} 1 \times \mathrm{HBSS}$ each, and centrifuged again $(2,700 \times \mathrm{g}$, $4^{\circ} \mathrm{C}$ for $\left.5 \mathrm{~min}\right)$. ChIP was performed with the AutoChipmentation Kit for histones (Diagenode, cat. C01011000). Crosslinked chromatin was resuspended in $100 \mu \mathrm{L}$ cold lysis buffer IL1 and incubated at $4^{\circ} \mathrm{C}$ for $10 \mathrm{~min}$ in a rotating well. Following centrifugation $\left(2,700 \times \mathrm{g}, 4^{\circ} \mathrm{C}\right.$ for $\left.5 \mathrm{~min}\right)$, the supernatant was discarded, and the pellet was resuspended in $100 \mu \mathrm{L}$ cold lysis buffer IL2, and incubated in a rotating well for $10 \mathrm{~min}$ at $4^{\circ} \mathrm{C}$. The suspension was centrifuged $\left(2,700 \times \mathrm{g}, 4^{\circ} \mathrm{C}\right.$ for $5 \mathrm{~min}$ ) and the pellet was resuspended in $100 \mu \mathrm{L}$ of complete shearing buffer iS1. Samples were sonicated with the Bioruptor Pico, over five cycles ( $30 \mathrm{~s}$ ON and $30 \mathrm{~s}$ OFF). They were then transferred to new tubes and centrifuged $(16,000 \times \mathrm{g}, 10 \mathrm{~min}$, $4^{\circ} \mathrm{C}$ ). The supernatants were transferred to new tubes, pooled by batch and $500 \mu \mathrm{L}$ iS1 was added. The ChIPmentation program was selected on the Diagenode SX-8G IP-Star Compact. We used the following parameters: $3 \mathrm{~h}$ of antibody coating at $4^{\circ} \mathrm{C}, 13 \mathrm{~h}$ of IP reaction at $4^{\circ} \mathrm{C}, 10 \mathrm{~min}$ wash at $4^{\circ} \mathrm{C}$ and 5 min tagmentation. All steps were performed with the intermediate mixing speed.

ChIP-buffer, antibody coating mix and immunoprecipitation mix were prepared in accordance with the supplied protocol.
Stripping, end repair and reverse cross-linking were performed with the reagents provided with the kit.

\section{Titration by qPCR}

The immunoprecipitated DNA was quantified by qPCR with a LightCycler480 (Roche System). The PCR mix was prepared with $2 \mu \mathrm{L}$ of immunoprecipitated chromatin, in a final volume of $10 \mu \mathrm{L}$ $\left(0.5 \mu \mathrm{L}\right.$ of each primer, $5 \mu \mathrm{L}$ of Eurogentec Takyon ${ }^{\mathrm{TM}}$ SYBR $^{\circledR} 2 \mathrm{x}$ qPCR Mastermix Blue). The following Light-Cycler run protocol was used: denaturation at $95^{\circ} \mathrm{C}$ for $3 \mathrm{~min}$; amplification and quantification $\left(40\right.$ cycles), $95^{\circ} \mathrm{C}$ for $30 \mathrm{~s}, 60^{\circ} \mathrm{C}$ for $30 \mathrm{~s}, 72^{\circ} \mathrm{C}$ for $30 \mathrm{~s}$. Cycle threshold $(\mathrm{Ct})$ was determined with the fit point method of LightCycler480 version 1.5. PCR was performed in triplicate, and the mean $\mathrm{Ct}$ was calculated.

Percent input recovery (\%IR) was calculated as described by Cosseau (Cosseau et al., 2009), with the following formula: $\% I R=$ $100\left(E^{C t \text { (input)-Ct(IPbound })}\right.$ where $\mathrm{E}$ is primer efficiency, Ct (input) is the Ct of the unbound fraction, and Ct (IPbound) is the Ct of the immunoprecipitated sample. Only antibodies reaching saturation were considered specific and were used for ChIPSeq experiments, at their optimal concentration (Supplementary Table S1 and Supplementary Figure S1).

\section{ChIP-Seq}

The same ChIP protocol was performed with the AutoChipmentation kit for histones (Diagenode,cat. C01011000), with specific antibodies validated for $M$. incognita, targeting the histone modifications H3K4me3 (Merck Millipore ref 04745, batch 2452485), H3K9me3 (Abcam ref ab8898, batch GR306402-2), H3K27ac (Abcam ref ab4729, batch GR1503672), H3K27me3 (Epigentek ref A-4039, batch 503019) and H4K20me1 (Abcam ref ab9051, batch GR158874-1). For each antibody, ChIP was performed in biological triplicate on two different M. incognita stages: eggs and J2s. The ChIP control was the input-control, consisting of a fraction of sheared chromatin without immunoprecipitation (Park, 2009).

Illumina libraries were constructed with primer indices provided by the Auto-Chipmentation kit for histones (Diagenode,cat. C01011000), according to the protocols supplied. The amount of DNA was determined and adjusted by qPCR quantification. Amplified libraries were quantified on a Bioanalyzer and sequenced by the BioEnvironnement platform (University of Perpignan, France) with an Illumina NextSeq 550 instrument generating 75 bp single-end reads. Sequencing reads have been deposited in the NCBI Sequence Read Archive (SRA, NCBI), under accession number PRJNA725801.

\section{ChIP-Seq Data Analysis}

Graphical representations were generated, and statistical analyses were performed with R version 3.6.1 (www.r-project.org) and the following libraries: chromstaR, cowplot, bamsignals, gplots, reshape2, tidyverse, ggpubr and rstatix.

Illumina read quality was analyzed with FastQC (Andrews, 2010). Read trimming was performed with Trim Galore (http:// www.bioinformatics.babraham.ac.uk/projects/trim_galore/), using the default parameters. Processed reads were mapped onto the reference genome of $M$. incognita (Blanc-Mathieu et al., 2017) 
with Bowtie2, using "Very sensitive end-to-end" presets (Langmead and Salzberg, 2012). All library sizes were downsampled to the size of the smallest library we had, corresponding to 3.7 million reads.

Peak calling for domain visualization in the $M$. incognita genome was performed with Peakranger (Feng et al., 2011). A fraction of sheared chromatin without immunoprecipitation has been used as input to subtract the background level. Normalized tracks were visualized with the Integrative Genome Viewer (Robinson et al., 2017). Biological replicates were treated independently, and reproducibility was checked manually (Supplementary Figure S2).

Enriched domain identification and chromatin state analysis were performed with ChromstaR, using the differential mode with default parameters, except for bin size and step size, which were set at $500 \mathrm{bp}$ and $250 \mathrm{bp}$, respectively (Taudt et al., 2016). ChromstaR uses a hidden Markov model approach to predict domains displaying enrichment. The three biological replicates were treated jointly by ChromstaR to generate the HMM model. Peak prediction for each histone modification was defined by a posterior probability $>0.5$.

The genomic frequencies of the histone modifications were calculated with ChromstaR and correspond to the percentage of bin sizes $(\sim 500 \mathrm{bp})$ with histone modifications and their combinations (defined as the overlapping of multiple modifications on the same bin) over the $184 \mathrm{Mb}$ of the $M$. incognita genome. As an example, $\mathrm{H} 3 \mathrm{~K} 4 \mathrm{me} 3$ frequency (\%) corresponds to the total covered bases ( $25 \mathrm{MB})$ divided by the genome size $(\sim 184 \mathrm{MB})$ and multiplied by 100 .

Analyses of enrichment at genomic elements were performed by plotting ChromstaR heatmaps. Heatmaps were generated from the logarithm (observed/expected) ratio. The "expected" parameter corresponds to the probability of a bin to be both a genomic element and marked with histone modification at the same location. The "observed" parameter constitutes the frequency of a bin corresponding to be both a genomic element and marked with histone modification at the same location. When the ratio is $>0$, the genomic element is observed more frequently than expected and considered as statistically enriched with the histone modification. We used genome annotation data from a previous genome sequencing analysis of $M$. incognita, including 43,718 protein-coding genes (corresponding to mRNA annotation) (Blanc-Mathieu et al., 2017). Furthermore, canonical TEs were annotated and filtered using REPET (Andrews, 2010; Kozlowski et al., 2021). Regions of differential enrichment were determined with a minimum differential posterior, to detect pairwise differences at $p=$ 0.9999 .

\section{Transcription Analysis and Histone Modification Profile}

RNA-seq data were provided by previous analyses of different life stages, eggs and J2s, of the nematode (Blanc-Mathieu et al., 2017). Data was reprocessed by Kozlowski and coworkers (Kozlowski et al., 2021), to generate FPKM values. Raw FPKM values were transformed to obtain $\log ($ median FPKM +1$)$ values, keeping the median of the three biological replicates as a representative value. Raw FPKM values are available online (Danchin and Da Rocha, 2020). The number of genes associated with histone modifications was calculated by determining whether the gene position overlapped a position of histone modification enrichment by at least $1 \mathrm{bp}$. A boxplot representing the levels of gene expression associated with the five histone modifications was generated for genes for which expression data were available. A Kruskal-Wallis test was performed, followed by a pairwise Dunn test, to identify significant differences in gene expression level between different histone modifications; with a $p$ value $<0.05$ was considered significant.

The mean enrichment profiles were calculated by ChromstaR, based on the $\log$ (expected/observed) enrichment from $2 \mathrm{~kb}$ upstream to $2 \mathrm{~kb}$ downstream from the protein-coding genes, considering only the top and bottom $10 \%$ of genes ranked according to expression level associated with the five histone modifications.

Differentially expressed genes were identified using previous RNA-seq data (Danchin et al., 2013; Blanc-Mathieu et al., 2017) processed by DE-seq2 (Love et al., 2014), a $p$ value $<0.05$ was considered significant and a fold-change $>2$ for overexpression.

\section{GO Enrichment Analysis}

GO term enrichment was analyzed with the $\mathrm{R}$ package GOfuncR, using default parameters. The FWER cutoff was set at 0.05 to identify overrepresented GO terms. (-) $\log _{10}$ (pvalue) was calculated for the representation of GO terms, more specifically "Biological Processes." All $M$. incognita genes associated with GO terms were used as references for GO enrichment analysis 1) for genes associated with $\mathrm{H} 3 \mathrm{~K} 4 \mathrm{me} 3$ only; and 2) for genes both associated with $\mathrm{H} 3 \mathrm{~K} 4 \mathrm{me} 3$ only and differentially expressed during eggs-to-J2s transition.

M. incognita orthologs were identified from a previous work (Pratx et al., 2017) using FamilyCompanion to identify orthologous links with 20 other species. Searches for GO terms for C. elegans orthologs were performed with the functional classification included in the PANTHER webtool (Thomas, 2003).

\section{DATA AVAILABILITY STATEMENT}

The datasets presented in this study can be found in online repositories. The names of the repository/repositories and accession number(s) can be found below: https:/www.ncbi. nlm.nih.gov/, PRJNA725801.

\section{AUTHOR CONTRIBUTIONS}

RH-G, PA, CG, and LP-B have made substantial contributions to the conception and design of the work. RH-G, NM-G, CG, and LP-B have made substantial contributions to the acquisition of data. RH-G, RC, AP, BF, MR, ED, PA, CG, 
and LP-B have made substantial contributions to the analysis of data. RH-G, BF, ED, PA, CG, and LP-B have made substantial contributions to the interpretation of data and have written the manuscript. All the authors, RH-G, RC, NMG, AP, BF, MR, ED, PA, CG, and LP-B have approved the submitted version and have agreed both to be personally accountable for the author's own contributions and to ensure that questions related to the accuracy or integrity of any part of the work, even ones in which the author was not personally involved, are appropriately investigated, resolved, and the resolution documented in the literature. CG and LP-B are the corresponding authors.

\section{FUNDING}

This work was supported by INRAE and the French Government (National Research Agency, ANR) through the ANR-18-CE200002 (ADMIRE), LABEX SIGNALIFE ANR-11-LABX-0028 and IDEX UCAJedi ANR-15-IDEX-0 programs. With the support of LabEx CeMEB, an ANR "Investissements d'avenir » program (ANR-10-LABX-04-01). This study is set within the framework of the "Laboratoire d'Excellence (LabEx) " TULIP (ANR-10LABX-41).

\section{REFERENCES}

Ahringer, J., and Gasser, S. M. (2018). Repressive Chromatin in Caenorhabditis elegans: Establishment, Composition, and Function. Genetics 208 (2), 491-511. doi:10.1534/genetics.117.300386

Alla, R. K., and Cairns, B. R. (2014). RNA Polymerase III Transcriptomes in Human Embryonic Stem Cells and Induced Pluripotent Stem Cells, and Relationships with Pluripotency Transcription Factors. PLoS ONE 9 (1), e85648. doi:10.1371/journal.pone.0085648

Andrews, S. (2010). FastQC - A Quality Control Tool for High Throughput Sequence Data. Babraham Bioinformatics. Available at: http://www.bioinformatics. babraham.ac.uk/projects/fastqc/.

Asamizu, E., Shirasawa, K., Hirakawa, H., and Iwahori, H. (2020). Root-knot Nematode Genetic Diversity Associated with Host Compatibility to Sweetpotato Cultivars. Mol. Plant Pathol. 21 (8), 1088-1098. doi:10.1111/ mpp.12961

Barski, A., Cuddapah, S., Cui, K., Roh, T.-Y., Schones, D. E., Wang, Z., et al. (2007). High-Resolution Profiling of Histone Methylations in the Human Genome. Cell 129 (4), 823-837. doi:10.1016/j.cell.2007.05.009

Battle, S. L., Doni Jayavelu, N., Azad, R. N., Hesson, J., Ahmed, F. N., Overbey, E. G., et al. (2019). Enhancer Chromatin and 3D Genome Architecture Changes from Naive to Primed Human Embryonic Stem Cell States. Stem Cel Rep. 12 (5), 1129-1144. doi:10.1016/j.stemcr.2019.04.004

Bebber, D. P., Holmes, T., and Gurr, S. J. (2014). The Global Spread of Crop Pests and Pathogens. Glob. Ecol. Biogeogr. 23 (12), 1398-1407. doi:10.1111/geb.12214

Bian, Q., Anderson, E. C., Yang, Q., and Meyer, B. J. (2020). Histone H3K9 Methylation Promotes Formation of Genome Compartments inCaenorhabditis Elegansvia Chromosome Compaction and Perinuclear Anchoring. Proc. Natl. Acad. Sci. USA 117 (21), 11459-11470. doi:10.1073/pnas.2002068117

Blanc-Mathieu, R., Perfus-Barbeoch, L., Aury, J.-M., Da Rocha, M., Gouzy, J., Sallet, E., et al. (2017), Hybridization and Polyploidy Enable Genomic Plasticity without Sex in the Most Devastating Plant-Parasitic Nematodes;13(6): e1006777. doi:10.1371/journal.pgen.1006777

Boyer, L. A., Plath, K., Zeitlinger, J., Brambrink, T., Medeiros, L. A., Lee, T. I., et al.(2006). Polycomb Complexes Repress Developmental Regulators in Murine Embryonic Stem Cells. Nature 441, 349-353. doi:10.1038/nature04733

\section{ACKNOWLEDGMENTS}

We would like to thank Jean-François Allienne and the IHPE team (Perpignan, France) for ChIP sample preparation and sequencing. We thank Dr. Marc Bailly-Bechet, Dr. Dominique Collinet, Julie Dazenière, Dr. Georgios Koutsovoulos and Dr. Djampa Kozlowski (ISA Sophia Antipolis, France) for assistance with and discussions about data analysis and statistics. We also thank Yongpan Chen, Dr. Joffrey Mejias, Yara Nourredine, Laura Perrot and Salomé Soulé (ISA Sophia Antipolis, France) for their help in the preparation of biological materials and fruitful discussion. We also thank Dr. Michael Quentin (ISA Sophia Antipolis, France) for help with effector analysis. We thank all the members of the IPN team for insightful discussions and technical help. We also thank Corinne Rancurel and PlantBios's BIG bioinformatics platform for technical support (ISA Sophia Antipolis, France).

\section{SUPPLEMENTARY MATERIAL}

The Supplementary Material for this article can be found online at: https:/www.frontiersin.org/articles/10.3389/fcell.2021.765690/ full\#supplementary-material

Bracken, A. P. (2006). Genome-wide Mapping of Polycomb Target Genes Unravels Their Roles in Cell Fate Transitions. Genes Dev. 20 (9), 1123-1136. doi:10.1101/ gad. 381706

Caillaud, M.-C., Dubreuil, G., Quentin, M., Perfus-Barbeoch, L., Lecomte, P., de Almeida Engler, J., et al. (2008). Root-knot Nematodes Manipulate Plant Cell Functions during a Compatible Interaction. J. Plant Physiol. 165 (1), 104-113. doi:10.1016/j.jplph.2007.05.007

Caillaud, M.-C., and Favery, B. (2016). "In Vivo Imaging of Microtubule Organization in Dividing Giant Cell. Methods. Molecular. Biol., 137-144. doi:10.1007/978-1-4939-3142-2_11

Castagnone-Sereno, P., Mulet, K., Danchin, E. G. J., Koutsovoulos, G. D., Karaulic, M., Da Rocha, M., et al. (2019). Gene Copy Number Variations as Signatures of Adaptive Evolution in the Parthenogenetic, Plant-Parasitic Nematode Meloidogyne incognita. Mol. Ecol. 28 (10), 2559-2572. doi:10.1111/mec.15095

Castagnone-Sereno, P., and Danchin, E. G. J. (2014). Parasitic success without Sex the Nematode Experience. J. Evol. Biol. 27 (7), 1323-1333. doi:10.1111/ jeb. 12337

Castagnone-Sereno, P. (2006). Genetic Variability and Adaptive Evolution in Parthenogenetic Root-Knot Nematodes. Heredity 96 (4), 282-289. doi:10.1038/sj.hdy.6800794

Choi, J. Y., and Lee, Y. C. G. (2020). Double-edged Sword: The Evolutionary Consequences of the Epigenetic Silencing of Transposable Elements. Plos Genet. 16 (7), e1008872. doi:10.1371/journal.pgen.1008872

Connolly, L. R., Smith, K. M., and Freitag, M. (2013). The Fusarium Graminearum Histone H3 K27 Methyltransferase KMT6 Regulates Development and Expression of Secondary Metabolite Gene Clusters. Plos Genet. 9 (10), e1003916. doi:10.1371/journal.pgen.1003916

Cosseau, C., Azzi, A., Smith, K., Freitag, M., Mitta, G., and Grunau, C. (2009). Native Chromatin Immunoprecipitation (N-ChIP) and ChIP-Seq of Schistosoma Mansoni: Critical Experimental Parameters. Mol. Biochem. Parasitol. 166 (1), 70-76. doi:10.1016/j.molbiopara.2009.02.015

Da Rocha, M., Bournaud, C., Dazenière, J., Thorpe, P., Pellegrin, C., Bailly-Bechet, M., et al. (2021). Genome Expression Dynamics Reveals Parasitism Regulatory Landscape of the Root-Knot Nematode Meloidogyne incognita and a Promoter Motif Associated with Effector Genes. GENES 12, 771. doi:10.3390/ genes 12050771 
Danchin, E. G. J., and Da Rocha, M. M. (2020). Incognita Protein-Coding Genes Expression Patterns. Portail Data INRAE. doi:10.15454/YM2DHE.2020

Danchin, E. G. J., Arguel, M.-J., Campan-Fournier, A., Perfus-Barbeoch, L., Magliano, M., Rosso, M.-N., et al. (2013). Identification of Novel Target Genes for Safer and More Specific Control of Root-Knot Nematodes from a Pan-Genome Mining. Plos Pathog. 9 (10), e1003745. doi:10.1371/ journal.ppat.1003745

Dong, X., and Weng, Z. (2013). The Correlation between Histone Modifications and Gene Expression. Epigenomics 5 (2), 113-116. doi:10.2217/epi.13.13

Favery, B., Dubreuil, G., Chen, M.-S., Giron, D., and Abad, P. (2020). Gall-Inducing Parasites: Convergent and Conserved Strategies of Plant Manipulation by Insects and Nematodes. Annu. Rev. Phytopathol. 58 (1), 1-22. doi:10.1146/ annurev-phyto-010820-012722

Feng, X., Grossman, R., and Stein, L. (2011). PeakRanger: A Cloud-Enabled Peak Caller for ChIP-Seq Data. BMC Bioinformatics 12 (1), 139. doi:10.1186/14712105-12-139

Garcia, B. A., Hake, S. B., Diaz, R. L., Kauer, M., Morris, S. A., Recht, J., et al. (2007). Organismal Differences in Post-translational Modifications in Histones H3 and H4. J. Biol. Chem. 282 (10), 7641-7655. doi:10.1074/jbc.m607900200

Gornik, S. G., Ford, K. L., Mulhern, T. D., Bacic, A., McFadden, G. I., and Waller, R. F. (2012). Loss of Nucleosomal DNA Condensation Coincides with Appearance of a Novel Nuclear Protein in Dinoflagellates. Curr. Biol. 22 (24), 2303-2312. doi:10.1016/j.cub.2012.10.036

Greer, E. L., Blanco, M. A., Gu, L., Sendinc, E., Liu, J., Aristizábal-Corrales, D., et al. (2015). DNA Methylation on N6-Adenine in C. elegans. Cell 161 (4), 868-878. doi:10.1016/j.cell.2015.04.005

He, J., Fu, X., Zhang, M., He, F., Li, W., Abdul, M. M., et al. (2019). Transposable Elements Are Regulated by Context-specific Patterns of Chromatin marks in Mouse Embryonic Stem Cells. Nat. Commun. 10 (1), 34. doi:10.1038/s41467018-08006-y

Hewezi, T. (2020). Epigenetic Mechanisms in Nematode-Plant Interactions. Annu. Rev. Phytopathol. 58 (1), 119-138. doi:10.1146/annurev-phyto-010820-012805

Huang, G., Dong, R., Allen, R., Davis, E. L., Baum, T. J., and Hussey, R. S. (2005). Developmental Expression and Molecular Analysis of Two Meloidogyne incognita Pectate Lyase Genes. Int. J. Parasitol. 35 (6), 685-692. doi:10.1016/ j.ijpara.2005.01.006

Koutsovoulos, G. D., Marques, E., Arguel, M. J., Duret, L., Machado, A. C. Z., Carneiro, R. M. D. G., et al. (2020). Population Genomics Supports Clonal Reproduction and Multiple Independent Gains and Losses of Parasitic Abilities in the Most Devastating Nematode Pest. Evol. Appl. 13 (2), 442-457. doi:10.1111/eva.12881

Kozlowski, D. K. L., Hassanaly-Goulamhoussen, R., Da Rocha, M., Koutsovoulos, G. D., Bailly-Bechet, M., and Danchin, E. G. J. (2021). Movements of Transposable Elements Contribute to the Genomic Plasticity and Species Diversification in an Asexually Reproducing Nematode Pest. Evol. Appl. 14, 1844. doi:10.1111/eva.13246

Lachner, M., O'Carroll, D., Rea, S., Mechtler, K., and Jenuwein, T. (2001). Methylation of Histone H3 Lysine 9 Creates a Binding Site for HP1 Proteins. Nature 410, 116-120. doi:10.1038/35065132

Langmead, B., and Salzberg, S. L. (2012). Fast Gapped-Read Alignment with Bowtie 2. Nat. Methods 9 (4), 357-359. doi:10.1038/nmeth.1923

Li, F., Wan, M., Zhang, B., Peng, Y., Zhou, Y., Pi, C., et al. (2018). Bivalent Histone Modifications and Development. Curr. Stem Cel Res Ther 13 (2), 83-90. doi:10.2174/1574888X12666170123144743

Lin, B., Lee, H., Yoon, J.-G., Madan, A., Wayner, E., Tonning, S., et al. (2015). Global Analysis of H3K4me3 and H3K27me3 Profiles in Glioblastoma Stem Cells and Identification of SLC17A7 as a Bivalent Tumor Suppressor Gene. Oncotarget 6 (7), 5369-5381. doi:10.18632/oncotarget. 3030

Love, M. I., Huber, W., and Anders, S. (2014). Moderated Estimation of Fold Change and Dispersion for RNA-Seq Data with DESeq2. Genome Biol. 15 (12), 550. doi:10.1186/s13059-014-0550-8

Meile, L., Peter, J., Puccetti, G., Alassimone, J., McDonald, B. A., and SánchezVallet, A. (2020). Chromatin Dynamics Contribute to the Spatiotemporal Expression Pattern of Virulence Genes in a Fungal Plant Pathogen. Editor A. Di Pietro (Washington, DC: MBio), doi:10.1128/mbio.02343-20

Mejias, J., Truong, N. M., Abad, P., Favery, B., and Quentin, M. (2019). Plant Proteins and Processes Targeted by Parasitic Nematode Effectors. Front. Plant Sci. 10, 970. doi:10.3389/fpls.2019.00970
Meyer, C. A., and Liu, X. S. (2014). Identifying and Mitigating Bias in NextGeneration Sequencing Methods for Chromatin Biology. Nat. Rev. Genet. 15 (11), 709-721. doi:10.1038/nrg3788

Mitreva, M., Jasmer, D. P., Zarlenga, D. S., Wang, Z., Abubucker, S., Martin, J., et al. (2011). The Draft Genome of the Parasitic Nematode Trichinella spiralis. Nat. Genet. 43 (3), 228-235. doi:10.1038/ng.769

Ngo, V., Chen, Z., Zhang, K., Whitaker, J. W., Wang, M., and Wang, W. (2019). Epigenomic Analysis Reveals DNA Motifs Regulating Histone Modifications in Human and Mouse. Proc. Natl. Acad. Sci. USA 116 (9), 3668-3677. doi:10.1073/ pnas. 1813565116

Nguyen, C.-N., Perfus-Barbeoch, L., Quentin, M., Zhao, J., Magliano, M., Marteu, N., et al. (2018). A Root-Knot Nematode Small glycine and Cysteine-Rich Secreted Effector, MiSGCR1, Is Involved in Plant Parasitism. New Phytol. 217 (2), 687-699. doi:10.1111/nph.14837

Ninova, M., Fejes Tóth, K., and Aravin, A. A. (2019). The Control of Gene Expression and Cell Identity by H3K9 Trimethylation. Development 146 (19), dev181180. doi:10.1242/dev.181180

Oda, H., Okamoto, I., Murphy, N., Chu, J., Price, S. M., Shen, M. M., et al. (2009). Monomethylation of Histone H4-Lysine 20 Is Involved in Chromosome Structure and Stability and Is Essential for Mouse Development. Mol. Cel Biol 29 (8), 2278-2295. doi:10.1128/mcb.01768-08

O'Kane, C. J., and Hyland, E. M. (2019). Yeast Epigenetics: the Inheritance of Histone Modification States. Biosci. Rep. 39 (5).

Park, P. J. (2009). ChIP-seq: Advantages and Challenges of a Maturing Technology. Nat. Rev. Genet. 10 (10), 669-680. doi:10.1038/nrg2641

Perfus-Barbeoch, L., Castagnone-Sereno, P., Reichelt, M., Fneich, S., Roquis, D., Pratx, L., et al. (2014). Elucidating the Molecular Bases of Epigenetic Inheritance in Non-model Invertebrates: The Case of the Root-Knot Nematode Meloidogyne incognita. Front Physiol 5, 211. doi:10.3389/ fphys.2014.00211

Pratx, L., Rancurel, C., Rocha, M. Da., Danchin, E. G. J., Castagnone-Sereno, P., Abad, P., et al. (2017). Genome-wide Expert Annotation of the Epigenetic Machinery of the Plant-Parasitic Nematodes Meloidogyne Spp ., with a Focus on the Asexual Species. BMC Genomics.

Robinson, J. T., Thorvaldsdóttir, H., Wenger, A. M., Zehir, A., and Mesirov, J. P. (2017). Variant Review with the Integrative Genomics Viewer. Cancer Res. 77 (21), e31. doi:10.1158/0008-5472.CAN-17-0337

Sacco, M. A., Koropacka, K., Grenier, E., Jaubert, M. J., Blanchard, A., Goverse, A., et al. (2009). The Cyst Nematode SPRYSEC Protein RBP-1 Elicits Gpa2- and RanGAP2-dependent Plant Cell Death. Plos Pathog. 5 (8), e1000564. doi:10.1371/journal.ppat.1000564

Shikata, D., Yamamoto, T., Honda, S., Ikeda, S., and Minami, N. (2020). H4K20 Monomethylation Inhibition Causes Loss of Genomic Integrity in Mouse Preimplantation Embryos. J. Reprod. Dev. 66 (5), 411-419. doi:10.1262/ jrd.2020-036

Singh, S. K., Hodda, M., and Ash, G. J. (2013). Plant-parasitic Nematodes of Potential Phytosanitary Importance, Their Main Hosts and Reported Yield Losses. EPPO Bull. 43 (2), 334-374. doi:10.1111/epp.12050

Soyer, J. L., Rouxel, T., and Fudal, I. (2015). Chromatin-based Control of Effector Gene Expression in Plant-Associated Fungi. Curr. Opin. Plant Biol. 26, 51. doi:10.1016/j.pbi.2015.05.025

Soyer, J. L., El Ghalid, M., Glaser, N., Ollivier, B., Linglin, J., Grandaubert, J., et al. (2014). Epigenetic Control of Effector Gene Expression in the Plant Pathogenic Fungus Leptosphaeria Maculans. Plos Genet. 10 (3), e1004227. doi:10.1371/ journal.pgen.1004227

Stillman, B. (2018). Histone Modifications: Insights into Their Influence on Gene Expression. Cell 175 (1), 6-9. doi:10.1016/j.cell.2018.08.032

Strahl, B. D., and Allis, C. D. (2000). The Language of Covalent Histone Modifications. Nature 403, 41-45. doi:10.1038/47412

Talbert, P. B., and Henikoff, S. (2010). Histone Variants - Ancient Wrap Artists of the Epigenome. Nat. Rev. Mol. Cel Biol 11 (4), 264-275. doi:10.1038/ nrm2861

Taudt, A., Nguyen, M. A., Heinig, M., Johannes, F., and Colomé-Tatché, M. (2016). Tracking Combinatorial Chromatin State Dynamics in Space and Time. bioRxiv. doi:10.1101/038612

Tessarz, P., and Kouzarides, T. (2014). Histone Core Modifications Regulating Nucleosome Structure and Dynamics. Nat. Rev. Mol. Cel Biol 15 (11), 703-708. doi:10.1038/nrm3890 
Thomas, P. D. (2003). PANTHER: A Library of Protein Families and Subfamilies Indexed by Function. Genome Res. 13 (9), 2129-2141. doi:10.1101/gr.772403

Tie, F., Banerjee, R., Stratton, C. A., Prasad-Sinha, J., Stepanik, V., Zlobin, A., et al. (2009). CBP-mediated Acetylation of Histone H3 Lysine 27 antagonizesDrosophilaPolycomb Silencing. Dev. 136(18):3131-3141. doi:10.1242/dev.037127

Weinhouse, C., Truong, L., Meyer, J. N., and Allard, P. (2018). Caenorhabditis elegans as an Emerging Model System in Environmental Epigenetics. Environ. Mol. Mutagen. 59 (7), 560-575. doi:10.1002/em.22203

Wenzel, D., Palladino, F., and Jedrusik-Bode, M. (2011). Epigenetics in C. elegans: Facts and Challenges. Genesis 49 (8), 647-661. doi:10.1002/dvg.20762

Zang, C., Schones, D. E., Zeng, C., Cui, K., Zhao, K., and Peng, W. (2009). A Clustering Approach for Identification of Enriched Domains from Histone Modification ChIP-Seq Data. Bioinformatics 25 (15), 1952-1958. doi:10.1093/ bioinformatics/btp340

Zhang, T., Zhang, Z., Dong, Q., Xiong, J., and Zhu, B. (2020). Histone H3K27 Acetylation Is Dispensable for Enhancer Activity in Mouse Embryonic Stem Cells. Genome Biol. 21 (1), 45. doi:10.1186/s13059-020-01957-w
Conflict of Interest: The authors declare that the research was conducted in the absence of any commercial or financial relationships that could be construed as a potential conflict of interest.

Publisher's Note: All claims expressed in this article are solely those of the authors and do not necessarily represent those of their affiliated organizations, or those of the publisher, the editors, and the reviewers. Any product that may be evaluated in this article, or claim that may be made by its manufacturer, is not guaranteed or endorsed by the publisher.

Copyright (C) 2021 Hassanaly-Goulamhoussen, De Carvalho Augusto, MarteuGarello, Péré, Favery, Da Rocha, Danchin, Abad, Grunau and Perfus-Barbeoch. This is an open-access article distributed under the terms of the Creative Commons Attribution License (CC BY). The use, distribution or reproduction in other forums is permitted, provided the original author(s) and the copyright owner(s) are credited and that the original publication in this journal is cited, in accordance with accepted academic practice. No use, distribution or reproduction is permitted which does not comply with these terms. 